\title{
Cognitive Impairment in Heart Failure: Landscape, Challenges, and Future Directions
}

OPEN ACCESS

Edited by:

Yan Zhang,

Peking University, China

Reviewed by:

Siting Feng

Capital Medical University, China

Xiaoyan Zhao,

The First Affiliated Hospital of

Zhengzhou University, China

*Correspondence:

Jingyi Ren

reniingyi1213@hotmail.com

tThese authors have contributed equally to this work

Specialty section:

This article was submitted to

General Cardiovascular Medicine,

a section of the journal

Frontiers in Cardiovascular Medicine

Received: 08 December 2021

Accepted: 30 December 2021

Published: 07 February 2022

Citation:

Yang $M$, Sun $D$, Wang $Y$, Yan $M$, Zheng J and Ren J (2022) Cognitive Impairment in Heart Failure:

Landscape, Challenges, and Future

Directions.

Front. Cardiovasc. Med. 8:831734.

doi: 10.3389/fcvm.2021.831734

\author{
Mengxi Yang ${ }^{1,2+}$, Di Sun ${ }^{1,2 \dagger}$, Yu Wang ${ }^{3}$, Mengwen Yan ${ }^{1,2}$, Jingang Zheng ${ }^{1,2}$ and \\ Jingyi Ren ${ }^{1,2,4 *}$
}

${ }^{1}$ Heart Failure Center, China-Japan Friendship Hospital, Beijing, China, ${ }^{2}$ Department of Cardiology, China-Japan Friendship Hospital, Beijing, China, ${ }^{3}$ Department of Neurology, China-Japan Friendship Hospital, Beijing, China, ${ }^{4}$ Vascular Health Research Center of Peking University Health Science Center, Beijing, China

Heart failure (HF) is a major global healthcare problem accounting for substantial deterioration of prognosis. As a complex clinical syndrome, HF often coexists with multi-comorbidities of which cognitive impairment $(\mathrm{Cl})$ is particularly important. $\mathrm{Cl}$ is increasing in prevalence among patients with HF and is present in around 40\%, even up to $60 \%$, of elderly patients with HF. As a potent and independent prognostic factor, $\mathrm{Cl}$ significantly increases the hospitalization and mortality and decreases quality of life in patients with HF. There has been a growing awareness of the complex bidirectional interaction between $\mathrm{HF}$ and $\mathrm{Cl}$ as it shares a number of common pathophysiological pathways including reduced cerebral blood flow, inflammation, and neurohumoral activations. Research that focus on the precise mechanism for $\mathrm{Cl}$ in $\mathrm{HF}$ is still ever insufficient. As the tremendous adverse consequences of $\mathrm{Cl}$ in HF, effective early diagnosis of $\mathrm{Cl}$ in $\mathrm{HF}$ and interventions for these patients may halt disease progression and improve prognosis. The current clinical guidelines in HF have begun to emphasize the importance of $\mathrm{Cl}$. However, nearly half of $\mathrm{Cl}$ in HF is underdiagnosed, and few recommendations are available to guide clinicians about how to approach $\mathrm{Cl}$ in patients with HF. This review aims to synthesize knowledge about the link between HF and cognitive dysfunction, issues pertaining to screening, diagnosis and management of $\mathrm{Cl}$ in patients with HF, and emerging therapies for prevention. Based on data from current studies, critical gaps in knowledge of $\mathrm{Cl}$ in HF are identified, and future research directions to guide the field forward are proposed.

Keywords: cognitive impairment, heart failure, epidemiology, pathophysiology, diagnosis, management

\section{INTRODUCTION}

Both heart failure (HF) and cognitive impairment (CI) are the important health concerns for older adults and loom as the public health problems in the coming decades due to the aging global population $(1,2)$. The similar epidemiological trends and the bidirectional feedback interactions between the heart and the brain are expected to cause a major increase in the prevalence of CI in HF (3). HF is generally considered a leading cause of hospitalization and mortality with an estimated prevalence of $>64$ million individuals worldwide $(4,5)$. CI is a very frequent comorbidity in patients with $\mathrm{HF}$ and is increasingly recognized as the major cause of chronic disability. It thus confers a substantial global burden to patients and healthcare systems. 
Cognitive function refers to a group of mental processes containing memory, language, executive function, visuospatial, concentration, and social cognition (6). The definition of CI is a clinical syndrome that acquires objective cognitive dysfunction affecting one or more cognitive domains. Using normative neuropsychological criteria, CI mostly refers to a performance 1.5 SD units lower than the population mean after accounting for demographics such as age and education. According to the impairment of activities of daily life, CI is classified into mild CI (MCI) and dementia (7). MCI is a stage between normal cognition and dementia that individuals, particularly, those with objective CI on neurocognitive testing and with largely preserved activities of daily living, have. Conversely, dementia is severe enough to affect independent activities of daily life (8).

Cognitive impairment (CI), including its extreme form dementia, has tremendous consequences not only for reduced HF self-care and independence, but also in limiting recognition and appropriate response to worsening HF symptoms of patients. This consequently deteriorates the prognosis of HF (9). It has been confirmed that HF contributes to cognitive decline and that the grade of CI correlates with the severity of HF. As a potent and independent prognostic factor, CI significantly increases the mortality in patients with HF (10). However, some degree of cognitive decline is typical in normal aging; hence, nearly half of CI in HF may be underdiagnosed (11). Therefore, identified $\mathrm{CI}$, especially the early diagnosis of MCI in the preclinical stage, may avoid the occurrence of dementia and, by optimal therapies, revert cognition to normal which has been considered as a crucial strategy for the improvement of prognosis and quality of life in HF population.

In this review, we synthesize knowledge about the landscape of $\mathrm{CI}$ in HF, the latest epidemiological data on CI in HF, the current understanding of heart and brain interaction, and the clinical diagnosis and assessment of CI in HF. We also address the potential therapeutic opportunities for preventing and halting the progression of CI in patients with HF. Based on data from current studies, we identify the critical gaps in knowledge of CI in HF and propose future research directions to guide the field forward.

\section{EPIDEMIOLOGY, PREVALENCE, AND PROGNOSTIC IMPLICATIONS OF CI IN HF \\ Epidemiology of $\mathrm{Cl}$ in the General Population}

Cognitive impairment (CI) remains a rising global epidemic, accounting for substantial morbidity. The prevalence rates of $\mathrm{CI}$ exponentially increase with increasing age, ranging from about $20 \%$ to more than $40 \%$ in general older adults (12-15). Dementia, the most severe state of CI, affects about 55 million of the adult population worldwide. The incidence of dementia in the general population is $1-2 \%$ per year. However, the incidence among patients with MCI that progressed to dementia is significantly higher, with an annual rate of $5-12 \%$, in community-based populations without intervention $(14,16,17)$ (Figure 1). The annual death rate was $8 \%$ among those with $\mathrm{CI}$, and the rate almost doubled if patients combined with additional medical conditions, such as heart disease (14).

\section{Prevalence of $\mathrm{Cl}$ in Patients With HF}

Cognitive impairment (CI) is overwhelmingly common and has become a severe burden in HF with a prevalence of 25-75\% across population-based studies due to variation in definitions and diagnostic criteria (Figure 2) (10, 11, 18-23). Accounting for age, the prevalence of CI in patients with HF is significantly higher compared with the general population. A multicenter survey conducted in Italy reported that about 35\% (526/1,511) of patients with HF were detected with CI, while only $29 \%$ $(3,448 / 11,790)$ of patients without HF were diagnosed with CI (10). A cross-sectional analysis from communities in US recruited 6,189 patients aged $\geq 67$ years. It also found that the age-adjusted prevalence of CI is about $40 \%$ in 707 patients with a moderate or high probability of $\mathrm{HF}$, of which more than one third were dementia. The odds of dementia in those with HF were 1.52-fold than that of non-HF patients with the adjustment of age, race, educational level, net worth, and self-reported prior stroke (23). Gallagher R et al. studied $128 \mathrm{HF}$ patients with an average age of 80 years. The odds of CI were increased more than 4 -fold

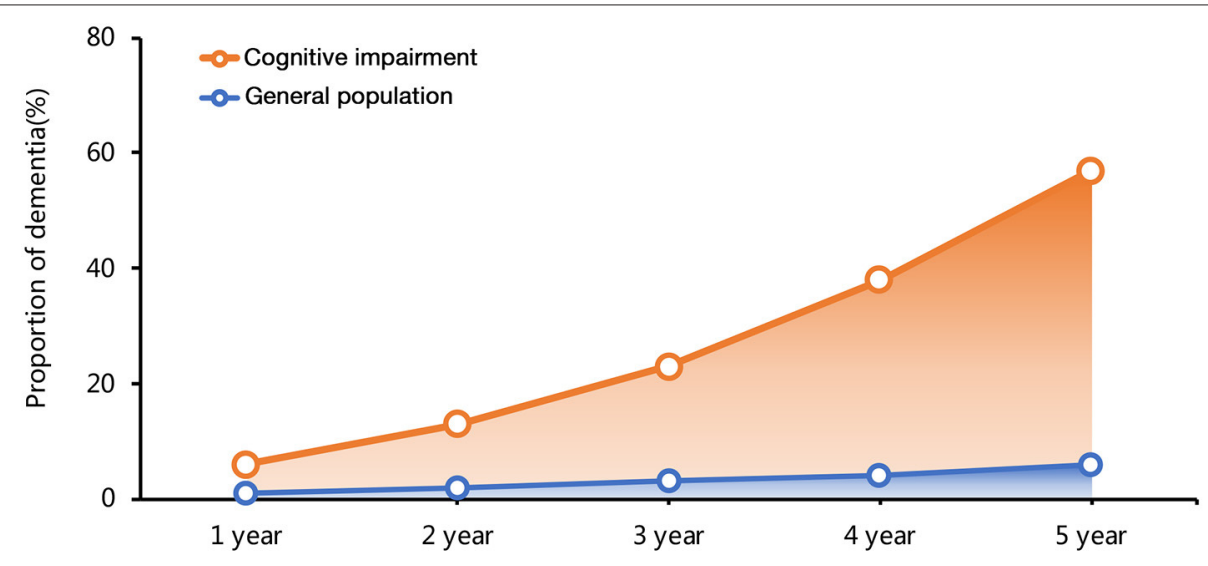

FIGURE 1 | The time curve of dementia incidence in general population and patients with cognitive impairment (CI). 


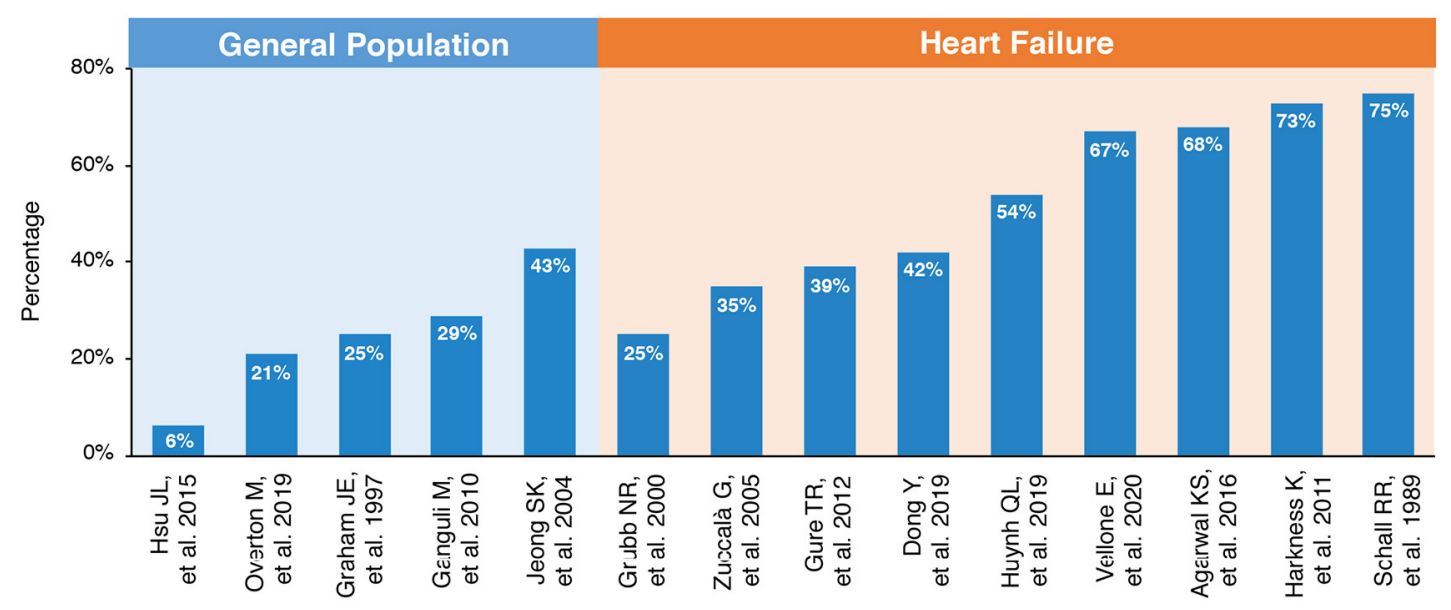

\begin{tabular}{|c|c|c|c|c|c|c|c|c|c|c|c|c|c|c|}
\hline Country & 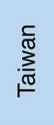 & $\begin{array}{l}\frac{c}{\Phi} \\
\frac{1}{0} \\
\text { क }\end{array}$ & 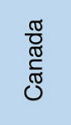 & 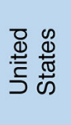 & 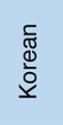 & 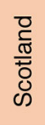 & $\stackrel{\text { Фे }}{\stackrel{\text { I }}{ \pm}}$ & 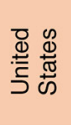 & $\begin{array}{l}\frac{0}{0} \\
\frac{0}{\pi} \\
\frac{0}{0} \\
\text { ஸ }\end{array}$ & 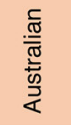 & $\begin{array}{l}\frac{*}{\widetilde{\pi}} \\
\frac{0}{0} \\
\frac{0}{0}\end{array}$ & 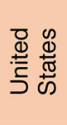 & 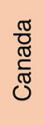 & 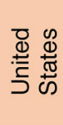 \\
\hline $\mathrm{N}$ & 276 & 3752 & 1255 & 1982 & 235 & 20 & 1151 & 707 & 96 & 1152 & 605 & 121 & 44 & 54 \\
\hline Mean age & 68 & 67 & $\geq 65$ & 77 & 74 & 68 & 78 & 79 & 59 & 72 & 67 & 79 & 76 & 46 \\
\hline $\begin{array}{l}\text { Mean } \\
\text { LVEF }\end{array}$ & - & - & - & - & - & 25 & - & - & 35 & 38 & 39 & - & 37 & 20 \\
\hline
\end{tabular}

FIGURE 2 | Prevalence of $\mathrm{Cl}$ in general population and patients with HF. *Including Sweden, Italy, Israel, The Netherlands, Germany, and the United States. Cl, cognitive impairment; HF, heart failure; LVEF, left ventricular ejection fraction.

in HF caused by ischemic heart disease compared with nonischemic $\mathrm{HF}$ (OR, 4.18; 95\% confidence interval, 1.15-15.69) $(24,25)$. With an exception for chronic HF, the Rehabilitation Therapy for Older Acute Heart Failure Patients (REHAB-HF) study revealed that $78 \%$ elderly patients hospitalized with acute decompensated HF had broad marked impairments in cognitive function. In addition, the prevalence of CI was similar in patients with preserved vs. reduced ejection fraction [EF; HF with preserved ejection fraction (HFpEF) and HF with reduced ejection fraction (HFrEF)] when adjusted for sex, body mass index (BMI), and comorbidities (26).

Furthermore, the occurrence and deterioration of $\mathrm{CI}$ in patients with HF has been demonstrated in longitudinal studies. Cardiovascular Health Study (CHS) enrolled 4,864 participants without a history of $\mathrm{HF}$ and of clinical stroke. After a diagnosis of $\mathrm{HF}$ at 80 years old, 5-year decline of cognitive functions was significantly worse compared with that in participants without $\mathrm{HF}$ of the same age period (27). Longitudinal data with a longer 8-year period of evaluating trajectories of 457 patients also demonstrated that congestive HF predicted cognitive decline (28).

\section{Multiple Cognitive Domain Impairments in $\mathbf{H F}$}

Recent studies have paid further attention to the detailed and multiple cognitive domains and spectrum of brain lesions in patients with HF. It is well-acknowledged that patients with HF typically exhibit CI in domains of memory, particularly in both verbal and visual memory, working memory, attention, processing speed, and executive function (29). A secondary analysis of Atherosclerosis Risk in Communities (ARIC) study supported that the risk of developing CI had no concern with HFpEF or HFrEF, while worse diastolic function was weakly but significantly associated with worse performance in memory, attention, and language due to abnormal cardiac hemodynamics (30). Similarly, Anna Frey et al. enrolled 148 patients with HF and determined that patients with HF exhibited cognitive deficits in the domains of attention and memory with a prevalence of 41 and $46 \%$, respectively. Furthermore, the degree of advanced medial temporal lobe atrophy (MTA) was strongly related to CI (31). Ichijo et al. assessed the frontal brain activity by near-infrared spectroscopy (NIRS) and non-invasively measured regional cerebral bold volume in patients with $\mathrm{HF}$, showing that frontal brain activity was significantly lower in the HF group than in the control subjects $(28.5$ vs. $88.0 \mathrm{mM} \mathrm{mm;} p<0.001)$ and significantly correlated with mini-mental state examination (MMSE) $(R=0.414, p=0.017)$ (32). Similar data from Asian populations indicated that the neuropsychological impairment in Asian patients with HF characterized vascular pathology with frequently impaired visuomotor speed (60\%), visuoconstruction (48\%), and visual memory (43\%) (11).

\section{Deterioration of Prognosis With $\mathrm{Cl}$ in HF}

Heart failure (HF) and CI accelerate each other, and CI would further worsen the cardiac function and prognosis of HF with higher mortality, hospitalization admission, and poor quality of life (QoL). As early as before the incident HF, CI is prevalent in patients with subclinical chronic heart disease at high-risk 
of chronic HF. A prior study supported that patients with MCI had 2-times higher risk with diastolic dysfunction and 1.7-times greater risk with other cardiac abnormalities (33). Moreover, the development of CI in patients with HF has an adverse impact on the clinical outcomes. Previous studies confirmed that CI was an independent risk factor for death and readmission in patients with HF, which increased the risk of cardiovascular mortality by $57 \%$ and the risk of all-cause death by $50 \%$. The prospective multi-center prevalence and prognostic value of social frailty in geriatric patients hospitalized for HF (FRAGILE-HF) study enrolled 1,180 patients with $\mathrm{HF}$ aged $\geq 65$ years, and $37.1 \%$ were identified as with CI using Mini-Cog. Further, they observed that coexistence of multiple frailty domains, including cognitive dysfunction, was prevalent in patients with $\mathrm{HF}$ readmission and all-cause death within 1 year (34). Similarly, Patel A et al. recruited 270 patients with $\mathrm{HF}$ and reported that the all-cause death and readmission rates of patients with CI were twice as high as those of patients without CI ( 46 vs. $22 \%, p<0.0001$ ) (35). In line with them, Hannes $\mathrm{H}$ et al. further recognized that worse scores of Montreal Cognitive Assessment (MoCA) heralded increased mortality and readmission risk. A study screened HF patients aged $\geq 70$ and found that patients with HF with CI had a significantly higher 30-day readmission rate than those without CI (26.8 vs. $12.8 \%$; $p<0.05$ ) (36). CHS study examined CI and other common comorbidities in 558 participants who developed incident $\mathrm{HF}$ and showed that CI was significantly associated with greater total mortality risk (37). Additional investigations regarding the cognitive functions were conducted and worse outcome were observed. Huynh QL et al. performed MoCA in 1,152 Australian patients with HF with a 12-months follow-up, suggesting that visuospatial/executive and orientation were the cognitive domains that were most predictive of post-discharge adverse outcomes in HF (18). It should also be noted that even MCI could deteriorate the prognosis of patients with HF.

It is widely endorsed that patients with HF are vulnerable to CI with serious consequences in healthcare and outcome, with interplay of poor self-care, incapacity of adhering to treatment regimens, and weakening daily living due to decreased attentions, memory, and execution abilities (38-40). On the other hand, the difficulties in describing symptoms would interfere with the recognition by doctors of worsening HF, resulting in the inability to adjust treatment strategy in time. Apart from the adverse outcome brought from poor disease management, CI also seriously impairs QoL and exercise capacity of patients. The secondary analysis of the Wii-HF trial, conducted with 605 patients, evaluated CI using MoCA and measured exercise capacity using a 6-min walk test (6MWT). It indicated that lower 6MWT scores were associated with five domains in cognitive function, including visuospatial/executive, naming, attention, language, and orientation (19).

\section{PATHOPHYSIOLOGY, CELLULAR MECHANISM, AND RISK FACTORS OF CI IN HF}

The underlying mechanism proposed for $\mathrm{CI}$ in $\mathrm{HF}$ is multifactorial but not fully elucidated. It is important to understand the pathophysiological mechanism regarding CI in HF for a promising diagnostic and therapeutic approach. Existing evidence indicated that hemodynamic alterations and molecular mechanisms may play important roles in the interaction between HF and CI. Also, common cardiovascular and non-cardiovascular comorbidities burden further link HF and CI with risk factors which have not been well established. A systematic summary addressing the potential pathophysiology and mechanisms is illustrated in Figure 3.

\section{Pathophysiology of $\mathrm{Cl}$ in $\mathrm{HF}$}

\section{Reduced Cerebral Blood Flow}

It has well-established that HF usually has unfavorable effect on cerebral perfusion with decreased cerebral blood flow (CBF) (41). According to previous studies, CBF could be reduced by nearly $14-30 \%$ in chronic HF depending on the severity and chronicity of HF. Despite this, it can be managed using medical treatment, cardiac resynchronization therapy, left ventricular assist devices and heart transplantation (42-46). Several factors determine the reduced $\mathrm{CBF}$ in patients with HF. In addition to the systematic hypoperfusion caused by reduced cardiac output (CO) and blood pressure (BP), the distortion of cerebrovascular autoregulation also appear to play critical roles in decreasing CBF (47). The cerebral autoregulation ability help maintain the adequate blood flow in the brain after using vasodilators. However, in patients with HF, microcirculatory changes, such as endothelial dysfunctions, reduced nitric oxide bioavailability, and vascular smooth muscle proliferations may lead to impaired cerebral autoregulation and abnormal cerebrovascular reactivity which appears as significant determinants of reduced CBF in HF (48).

Due to high metabolic demand and limited capacity for energy stores, the normal functions of brain highly depend on adequate perfusion to maintain normal nerve activity. Thus, the subtler alterations of CBF impairment and hypoperfusion due to cardiac dysfunctions could cause chronic brain injury, especially the vulnerable areas in the brain (49). A recent study further calculated the whole-brain CBF maps using MRI scanner and found that reduced CBF appeared in multiple areas involving bilateral prefrontal, frontal, temporal and occipital cortex, thalamus, cerebellum, corona radiate, corpus callosum, hippocampus, and amygdala, which regulate memory, decisionmaking executive functions, and language (50). Additionally, prior data has revealed that white matter lesions (WML) were expanded in patients with HF and was associated to CI (51, 52). This data is regarded as a manifestation of cerebral small vessels. The extensively decreased cerebral perfusion in cognitive regulatory sites is likely to contribute to cognitive deficits.

The deleterious effects of local CBF loss on cognitive function regarding molecular level have not been fully clarified, while hypoxia, reduced metabolic activity, and neurohormonal activations may play crucial roles to contribute to brain injury (53). Hypoxia caused by hypoperfusion induce the release of hypoxia inducible factor-1 (HIF-1) and increase the expression of vascular endothelial growth factor-1 (VEGF-1), resulting in increased permeability and disruption of the blood-brain barrier (BBB) by destroying the tight junctions $(54,55)$. Moreover, it has 


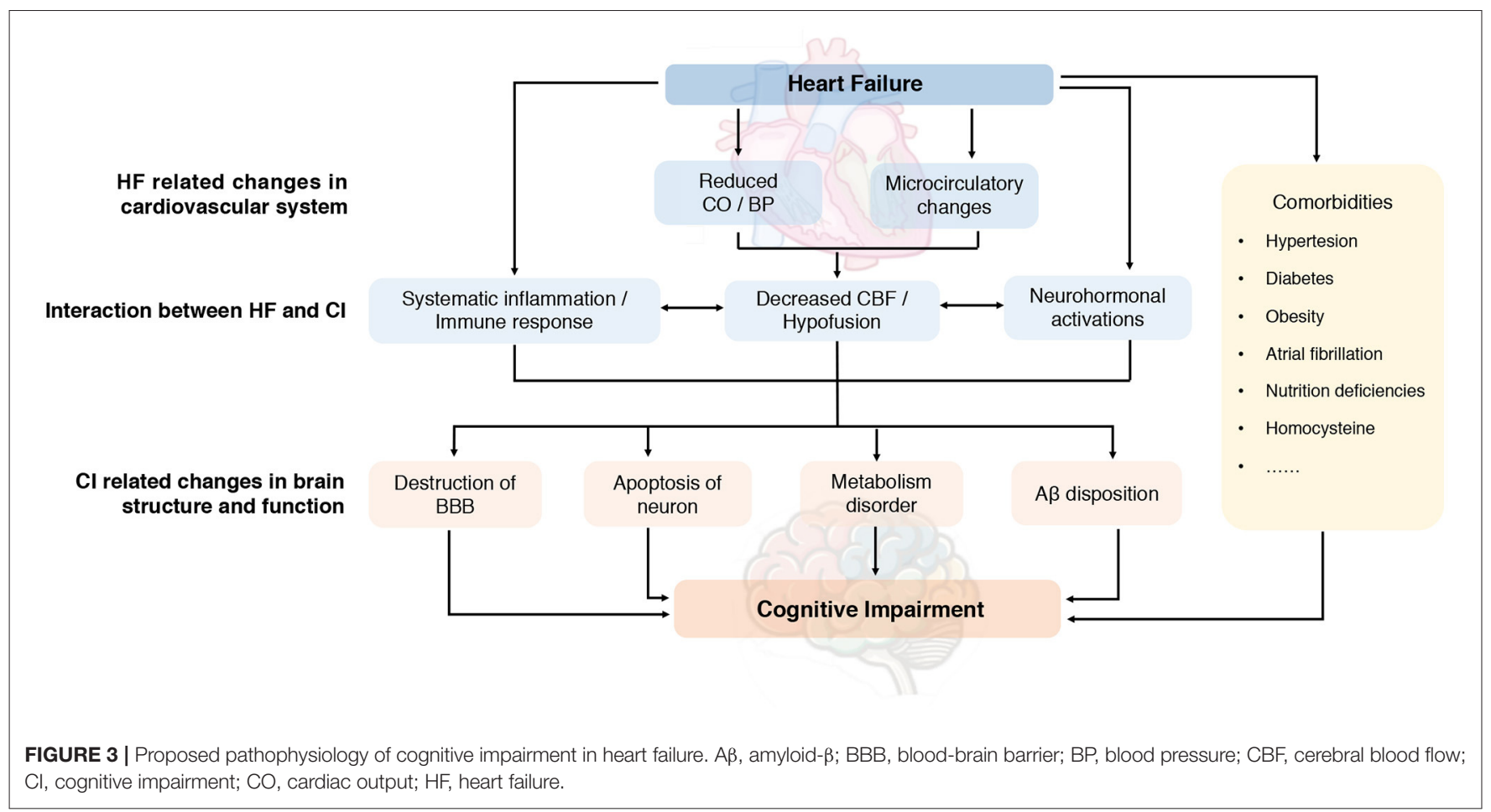

been shown that the reduced $\mathrm{CBF}$ and chronic perfusion could decrease the ability of glial cells to eliminate amyloid- $\beta(A \beta)$.

Even jeopardized CBF has commonly been considered to be the key explanations for $\mathrm{CI}$ in patients with $\mathrm{HF}$ as data on CBF in HFpEF with the similar manifestation of CI are still insufficient (56). Additionally, in the case of cortical gray matter loss with rich vasculature, reduced $\mathrm{CBF}$ did not seem to be the main causative factor (57), implying more pathological offenders should be investigated.

\section{Inflammation, Oxidation, and Immunity}

Amounting studies have shown that HF is considered as a state of systematic inflammation and that hypoperfusion in HF could contribute to local brain inflammation, which may also paly critical roles in development and deterioration of HF associated CI. Oxidative stress usually interplays with inflammation and is also proposed as one of the mechanisms in cognitive decline (58). Inflammatory factors, including interleukin-1 $\beta$ (IL-1 $\beta$ ), interleukin-6 (IL-6), tumor necrosis factor- $\alpha$ (TNF- $\alpha$ ), CRP, and interleukin-17A (IL-17) have been found to be inversely associated with cognitive functions in HF patients (59) as these remain significant after changes in LVEF and symptoms of HF. Additionally, animal models of HF also demonstrated that the expression of inflammatory genes, such as toll-like receptor4 (TLR-4), TNF- $\alpha$, and IL-6, were significantly upregulated in the cortex and hippocampus, particularly in the mouse (60). Cytokines regulate cognition by altering the synaptic plasticity and neurogenesis and directly inhibit the neurotransmitter cascade involved in learning and memory $(61,62)$. Among the proinflammatory factors, IL- $1 \beta$ and TNF- $\alpha$ seems to be the main driver and regulator in the inflammatory response, causing cell death via increasing neurotoxicity. IL- $1 \beta$ decreases the release of glutamate, which further affects the release of brain-derived neural factors and promotes the activation of protein kinase by p38 mitogen in the hippocampus, thus interfering with the memory and consolidation ability of hippocampus (63). ASK1p38-TNF- $\alpha$ is one of the key pathways involved in the disruption of the BBB, inducing the production of IL-6 (64). At the same time, IL- $1 \beta$ and TNF- $\alpha$ would upregulate the expression of CD73, which exert a protective effect on WHL by activation of glial cells and help to relieve inflammation via the counter-regulatory feedback (65).

Oxidative stress and immune response usually act synergistically. Increased level of circulating angiotensin II (Ang-II) during HF process induced perivascular macrophage (PVM) activation, which further regulate vascular permeability and recruit granulocyte. Upon Ang-II binds to angiotensin receptor 1 in the PVMs, the NADPH oxidase 2 is activated to promote ROS overproduction $(66,67)$. ROS, such as superoxide, $\mathrm{NO}$, and $\mathrm{ONOO}-$, increased $\mathrm{BBB}$ permeability via activating matrix metalloproteinase, producing oxidative damage to cellular molecules (68). Oxidative damage could also activate $\beta$-site amyloid precursor protein-cleaving enzyme-1 (BACE-1), resulting in increased synthesis of amyloid precursor protein (APP) and $A \beta(60,69)$. Meanwhile, the abnormality downregulated expressions of $\beta$-site amyloid precursor proteincleaving enzyme-2 (BACE-2) and contribute to reduced degradation of $A \beta$ precursor proteins.

During the process of $A \beta$ synthesis and deposition, evidence suggest that immune mediator, such as microglia and the 
macrophages in central nervous system, may contribute to the disease progression (70). Altered phenotype of microglia due to hypoperfusion result in impaired functions, which further reduce the elimination of $\mathrm{A} \beta$ (71). The high level of signal of translocator protein (TSPO) often indicate hyperactivated microglia. Thus, TSPO has been found as a useful marker to identify microglial activity. At the same time, active astrocytes express more amyloid precursor protein and cause an increasing $\mathrm{A} \beta$ production (72). Dendritic spines are important in learning and memory functions. When they are destroyed by excessive neurons, death, or $\mathrm{A} \beta$, CI would occur (73).

In brief, the inflammation, oxidative stress, and immune response aggravate cognitive functions mainly via disruption of the $\mathrm{BBB}$, damaging white matter and actitation of glial cells and, consequently, leading to CI (74).

\section{Neurohumoral Activations}

Although it has been well-documented that reduced $\mathrm{CO}$ and $\mathrm{CBF}$ are major drivers for $\mathrm{CI}$ in $\mathrm{HF}$, interestingly, $\mathrm{HFpEF}$ without diminished brain perfusion has also proven to be closely and independently associated with CI. Therefore, current data support the notion that CI in HFpEF may be associated with additional mechanisms independent of hypoperfusion, of which neurohumoral activations have caught increasing attractions (75). Exacerbated neurohumoral activations may alter neuronal functions and promote productions of CI-related proteins in cognitive areas.

Sympathetic nervous system and renin-angiotensin system (RAS) activation and elevated catecholamine levels in HF were related to poor cognitive performance. On one hand, the exaggerated sympathetic activity and RAS participate in the rightward shift of the lower limit of $\mathrm{CBF}$ autoregulation and lead to CBF reduction in patients with HF (45). On the other hand, it is speculated that increased level of catecholamines in HF could disturb Wnt signaling via inducing a loss of $\beta$-adrenergic pathway. Wnt/ $\beta$-catenin signaling has been implicated in the regulation of synaptic assembly, neurotransmission, and synaptic plasticity of hippocampus. Toledo et al. found that a rat with HF with normal EF displayed impaired learning process and memory loss. CI in the rats was correlated to the downregulated $\mathrm{Wnt} / \beta$ catenin signaling, which attenuated phosphorylated glycogen synthase kinase $3 \beta$ (p-GSK3 $\beta$ ) in the hippocampus and reduced synaptic plasticity, ultimately impairing cognitive functions (76, 77).

In addition, sustaining activation of the neuroendocrine system, such as hypothalamic-pituitary-adrenal axis, was suggested to have potential effects on progression of $\mathrm{HF}$ and structural damages of brain by regulating the neuronal metabolism, physiologies, and gene expressions. Glucocorticoid receptors are commonly expressed in neurons and glial cells with the highest levels in the hypothalamus, hippocampus, and amygdala brain structures, while the mineralocorticoid receptors expressed most in the hippocampus, amygdala, and prefrontal cortex edge. The two kinds of cortisol receptors play vital roles for the normal cognitive functions (78).

\section{Potential Cellular Mechanisms of $\mathbf{C l}$ in HF Disruption of Blood-Brain Barrier}

The complete BBB exert protective effects by preventing extravasation of toxic substances from circulation to the brain parenchyma. The increased permeability of BBB mainly caused by hypoperfusion and inflammation would lead to the influx of fluids, ions, albumin, and other proteins into neurons from the blood and cause infiltration of immune cells and secondary inflammation, further exacerbating brain edema, oxidative damage, luminal stenosis, and neuronal dysfunction, and ultimately lead to CI in patients with $\operatorname{HF}(79,80)$.

\section{Metabolism Disorder}

The normal energy metabolisms in the brain are high reliant on proper cardiac function, thus poor perfusion and ischemia lead to rapid consumption of adenosine triphosphate (ATP) and subsequent ROS are produced. Oxidative damage further increases the production of cytokines to induce specific inflammatory changes and lead to $\mathrm{A} \beta$ deposition eventually (81). In addition, mitochondrial dysfunction has been suggested as a key mechanism during development of CI in HF, as energy deficiency would result in functional abnormalities of central neurons which are intimately linked to cognitive functions (82). Incremental evidence indicated that mitochondria are also critical for neurodevelopment and neurogenesis, while mitochondrial degeneration could mediate CI through Wnt signaling pathway (83).

\section{Apoptosis of Neuron}

Loss of brain cells has been observed in lots of neurological diseases. Bax, a member of the Bcl-2 family, plays a key role in regulating apoptosis. Prior studies have found that the expressions of Bax in the hippocampal cortex changed female mice with HF, which may affect the apoptosis process of neurons related to cognitive function in the brain (84). Furthermore, evidence have shown that the expression of caspase family, especially caspase 3 and 6 , have been increased in the hippocampal tissue of mice with HF (85). Animal studies also found that the activation of the RAS in mice with HF can affect AMPK-PGC1 $\alpha$ signaling by stimulating angiotensin II receptors and increase the apoptosis of neural stem cells in the hippocampus of rats (86).

\section{Amyloid- $\beta$ Deposition}

Neuropathology of Alzheimer's disease (AD) such as $A \beta$ deposition is closely related to chronic hypoperfusion. In patients with $\mathrm{HF}$, a variety of pathways may participate in the accumulation and deposition of $\mathrm{A} \beta$ via increasing production and decreasing clearance, including CBF insufficiency, activation of microglia and astrocytes, inflammatory cascade, and oxidative imbalance. In turn, $A \beta$ could aggravate these pathological alterations and promote neurodegenerative process, forming a vicious circle. The accumulation of $\mathrm{A} \beta$ ultimately leads to $\mathrm{CI}$ in patients with $\mathrm{HF}$ (87). 


\section{Risk Factors Predicting $\mathrm{Cl}$ in Patients With HF}

Although it is well-known that patients with HF are more prone to cognitive decline, the predictors of developing CI have not been fully clarified. Some earlier studies and systematic reviews revealed that left ventricular ejection fraction (LVEF) and 6min walk tests (6MWT) were independently associated with development of CI in patients with HF. Recent work also pointed out that the high level of NT-proBNP was the independently predictor for CI in patients with HF $(11,88-90)$. In addition, the risk factors for dementia-related structural brain damage have also been explored. Karsten et al. observed a significant correlation between diminished gray matter density (GMD), decreased LVEF, increased NT-proBNP, and GMD in wide brain regions including the whole front median cortex along with the hippocampus and precuneus (91).

To date, the role of the well-established comorbidities in $\mathrm{CI}$, such as diabetes mellitus (DM) and hypertension, has been controversial in HF-associated CI. The longitudinal time-varying analysis of Warfarin vs. Aspirin in Reduced Ejection Fraction (WARCEF) trial disclosed that higher baseline cognitive status (MMSE scores), non-white race, older age, lower education, and NYHA $\geq$ II were independently associated with cognitive decline in $\mathrm{HF}$ while traditional cardiovascular risk factors containing hypertension, DM, and smoking seemed no association with cognitive decline (92).

Besides, additional comorbidities coexisting with $\mathrm{HF}$ contributed to $\mathrm{CI}$ have become gradually recognized by exerting inflammatory, metabolic, and neurohormonal pathways (31). Obesity, as a significant contributor to HF and, especially, HFpEF, has become an established risk factor for adverse brain changes and poor cognitive outcome in HF (93). Atrial fibrillation (AF) was also demonstrated to be significantly associated with CI independent of a history of stroke, exhibiting lower total brain, gray and white matter volumes related to poorer cognition, and increased risk of dementia $(94,95)$. The potential mechanism includes micro-emboli and hypoperfusion resulting from abnormal heart rate and $\mathrm{CO}$. Moreover, nutritional deficiencies are common in patients with HF due to absorption disorders of nutrition or diuretic use. Low level of folate, B12 vitamin, and albumin were correlated with CI and anemia (96). Animal models have demonstrated that thiamine deficiency caused brain atrophy and white matter changes, further affecting the learning ability in rats $(3,97)$. In addition, homocysteine levels due to renal insufficiency led to brain atrophy and brain cell apoptosis, further affecting neurogenesis and resulting in cognitive deficit (98).

\section{CLINICAL DIAGNOSIS AND ASSESSMENT FOR CI IN HF}

\section{Subjective Assessment}

Assessments, including subjective and objective, are crucial for the diagnosis of CI in HF. Whenever possible, history should be obtained both from the patient and from a family member, caregiver, or other reliable informant $(99,100)$. However, many
TABLE 1 | Screening tools used commonly in clinical practice for cognitive impairment $(\mathrm{Cl})$ diagnosis and assessment in general population.

\begin{tabular}{|c|c|c|c|c|}
\hline Classification & $\begin{array}{l}\text { Screening } \\
\text { tools }\end{array}$ & Cut points* & Sensitivity (\%) & $\begin{array}{c}\text { Specificity } \\
(\%)\end{array}$ \\
\hline \multirow[t]{6}{*}{$\mathrm{MCl}$} & MMSE (103) & $\leq 22 \sim 29$ & $62 \sim 85.5$ & $53.0 \sim 65.9$ \\
\hline & MoCA (103) & $\leq 22 \sim 27$ & $68.7 \sim 93.0$ & $63.9 \sim 100.0$ \\
\hline & Mini-Cog (109) & $\leq 2$ & 55 & 83 \\
\hline & CAMCOG (113) & $\leq 94$ & 72 & 76 \\
\hline & RCS (111) & $\leq 7$ & 87 & 70 \\
\hline & SLUMS (110) & $\leq 23.5 \sim 25.5$ & $92 \sim 100$ & $55 \sim 81$ \\
\hline \multirow[t]{6}{*}{ Dementia } & MMSE (104-106) & $\leq 23 \sim 26$ & $87 \sim 89$ & 82 89 \\
\hline & MoCA (105) & $\leq 17 \sim 23$ & 93 & 90 \\
\hline & Mini-Cog (106) & $\leq 2$ & 76 99 & 89 96 \\
\hline & CAMCOG (114) & $\leq 92 \sim 93$ & 100 & 95 \\
\hline & $\operatorname{RCS}(111)$ & $\leq 5$ & 89 & 94 \\
\hline & SLUMS (110) & $\leq 19.5 \sim 21.5$ & 100 & $91 \sim 98$ \\
\hline
\end{tabular}

*The cut points for diagnosis of mild $\mathrm{Cl}(\mathrm{MCl})$ are dependent on the population norms, age, educational level, and comorbidities, estimates of premorbid cognitive function. MMSE, mini-mental state examination; MoCA, montreal cognitive assessment; SLUMS, Saint Louis University mental status; RCS, rapid cognitive screen; CAMCOG, Cambridge cognitive examination.

patients with HF and their families accept cognitive decline as part of normal aging, and will declare themselves normal on the grounds that they are no worse than others their age. Therefore, subjective concerns alone are insufficient for diagnosis.

\section{Neuropsychological Tests}

The objective assessment requires to accomplish one or more standardized neuropsychological tests. Neuropsychological assessment of specific cognitive domains is preferred for both detecting mild impairments and for differential diagnosis. Diagnostic for CI in patients with $\mathrm{HF}$ are the same as in populations without HF. Previous studies have shown that the identification of CI by the screening tools was more accurate than the diagnosis by symptoms alone for patients with HF (101). More importantly, early diagnosis and therapy of CI could significantly reduce the 6 -month readmission rate and mortality in patients with HF (101).

Multiple neuropsychological tests are available for CI assessment, including the MMSE (102-106), the MoCA (103, 105, 107), the Mini-Cog $(108,109)$, the Saint Louis University mental status (SLUMS) (110), the rapid cognitive screen (RCS) (111), and the Cambridge cognitive examination (CAMCOG) (112-114). MMSE and MoCA are the most frequently used tests in clinical practices. Due to different cut points, the sensitivity and specificity of screening tools are different (Table 1). It is critically important that the test performance of a patient be interpreted in accordance with norms for the age, educational level of that patient, and preferably for his/her cultural/linguistic group and region as well.

Nowadays, the diagnostic accuracy of neuropsychological tests to screen for CI in populations with HF varies widely in studies. In a study to evaluate the usefulness of MoCA and MMSE compared with the golden standard European Consortium 
Criteria for diagnosing MCI in HF population, the sensitivity and specificity of MoCA were 82 and $91 \%$ and MMSE were 9 and $91 \%$ (115). Hawkins et al. also compared the ability of the MMSE and MoCA to detect CI in patients with HF (116). Both tests are useful in identifying the majority of patients with and without CI with the sensitivity and specificity around $60-70 \%$. Other tests, such as the Mini-Cog and the CAMCOG, had a moderate accuracy in populations with $\mathrm{HF}(117,118)$. With up and coming research investigating $\mathrm{CI}$ in $\mathrm{HF}$, however, there is still no clear consensus regarding the optimal screening tool for the assessment of CI in HF. The evidence on how and when best to screen cognitive in patients with HF is needed.

\section{Biomarkers}

The neuropsychological tests only have a moderate accuracy for the assessment of CI, thus there is a large need of special biomarkers to support the clinical diagnosis. Cerebrospinal fluid (CSF) biomarkers that reflect the pathophysiology of CI have been increasingly used and are the most common test in neurology to identify CI. Circulating biomarkers would be preferable, as blood is more accessible than CSF. However, only a fraction of brain proteins enters the circulatory system due to the BBB. Of note, considering that patients with $\mathrm{HF}$ and CI have multiple pathologies, a broader panel of biomarkers reflecting neuro injury, inflammation, and oxidative stress would be needed.

\section{Cerebrospinal Fluid Biomarkers}

The exploration of biomarkers in CSF has focused on the core molecules of $C I$ pathogenesis, including $A \beta$ and tau proteins $(119,120)$. Numerous studies demonstrated that a marked decrease of $A \beta 42$ in CSF can predict and identify CI due to cortical amyloid deposition in the brain $(121,122)$. In patients with $\mathrm{AD}$, the degree of increase in CSF total tau is around $300 \%$ of control levels (123). A meta-analysis of 51 studies suggested that p-tau is also a satisfactory prognostic biomarker for progression of MCI (124).

However, the lumbar puncture for CSF testing is a rare to be accepted in patients with HF, although it is safe and cheap. Recent research investigated the associations of LVEF with CSF biomarkers in older adults (125). Results showed that participants with lower LVEF had higher levels of CSF t-tau and t-tau/A $\beta 42$ ratios. There are few research focusing on the CSF biomarker in HF population. The biomarkers testing is still highly dependent on blood samples which are relatively convenient and suitable in clinical practice.

\section{Circulating Biomarkers Amyloid- $\beta$ in Plasma}

Amyloid- $\beta 42$ (A $\beta 42)$ is the most extensively studied blood biomarker for the diagnosis of symptomatic and prodromal $\mathrm{AD}$ and CI. Several studies reported plasma $A \beta$ as a potentially useful biomarkers for the early diagnosis of cognitive dysfunction and for the prediction of its progression in Parkinson's disease and amnestic MCI $(126,127)$. However, Bayes-Genis et al. measured circulating $A \beta 40$ in 939 consecutive patients with $\mathrm{HF}$ and found that there were no differences in circulating $A \beta 40$ levels in $\mathrm{HF}$ patients with and without $\mathrm{CI}$ at baseline or during follow-up over a median of 4 years (128). Interestingly, in multivariable analysis, including relevant clinical predictors and N-terminal pro-brain natriuretic peptide (NT-proBNP), A 340 remained significantly associated with all-cause (HR, 1.22; 95\%CI, 1.10-1.35; $p<0.001)$ and cardiovascular death (HR, 1.18; 95\%CI, 1.03-1.36; $p=0.02)$, but not with HF-related death (HR, 1.13; 95\%CI, 0.93-1.37; $p$ $=0.22$ ). Further studies are warranted to identify whether the bloodstream $A \beta$ concentration results in or facilitates $A \beta$ plaque formation in the brain in HF patients.

\section{Inflammatory Factors in Plasma}

Heart failure (HF) is considered a state of increased inflammatory responses which induce cognitive dysfunction involved in memory loss and impaired executive function. Redwine LS et al. investigated outpatients with $\mathrm{HF}$ and found that lower MoCA scores are associated with higher levels of plasma inflammatory biomarkers, such as interferon- $\gamma$ (IFN- $\gamma$ ), tumor necrosis factor$\alpha$ (TNF- $\alpha)$, and soluble vascular cell adhesion molecule-1 (sVCAM-1) (129). In an exploratory parallel design study of 69 patients with symptomatic HF, it was observed that changes in C-reactive protein (CRP) and IL-6 levels predicted alterations in MoCA scores (130).

\section{Cortisol in Plasma}

Cortisol was indicated to influence cognitive function. Elevated serum levels of cortisol were observed in patients with $\mathrm{HF}$ compared with healthy controls. More importantly, significantly higher levels of cortisol were found in patients with HF who had symptoms of depression and CI than those free from these symptoms. Besides, matched patients treated with cortisol performed worse on specific cognitive assessments compared with those treated with placebo, suggesting that cortisol levels in HF might influence the development of CI.

\section{Natriuretic Peptide in Plasma}

Elevated brain natriuretic peptide (BNP) and NT-proBNP are also associated with CI and increased risk for dementia in patients with HF. In recent years, there have been major advances in the development of blood-based biomarkers for CI. However, the sensitivity and specificity of a single circulating biomarker are not significant. Hence, a combination of biomarkers may offer a better diagnosis value for $\mathrm{CI}$ in $\mathrm{HF}$.

\section{Potential Biomarkers in Blood}

Recent developments have also given some novel circulating candidate biomarkers for CI. The novel N-terminal tau fragment (NT1) in plasma is not only a biomarker to distinguish normal, MCI, and AD dementia populations with high specificity and sensitivity, but is also a strong predictor of future cognitive decline and neurodegeneration in healthy elderly individuals $(131,132)$. A parallel metabolomics analysis in both the brain and blood conducted by Varma et al. identified 26 metabolites from two main classes, sphingolipids and glycerophospholipids, consistently associated with severity and progression of $\mathrm{AD}$ (133). Abdullah et al. found that the serum flotillin levels significantly decreased in patients with $\mathrm{AD}$ compared with those of non-AD controls, suggesting flotillin, the abundant 
exosome protein, may be a novel diagnostic marker for $\mathrm{AD}$ (134). However, these biomarkers mainly target in $\mathrm{AD}$ in the general population. Further studies are needed to validate these findings in patients with CI, especially in patients with $\mathrm{HF}$ and CI. Additional technical developments of novel ultrasensitive immunoassay and mass spectrometry methods show promise for blood biomarkers with potential applications as screening tools for $\mathrm{CI}$ in $\mathrm{HF}$.

\section{Neuroimaging}

Neuroimaging has contributed to our understanding of the mechanisms by which HF may lead to CI and is recommended by guidelines for CI diagnosis. Structural changes of brain, such as increased white matter hyperintensities, gray matter loss, and brain atrophy, are frequently encountered imaging findings in patients with $\mathrm{HF}$ with $\mathrm{CI}$ and often preceded by functional changes.

\section{Structural Brain Changes in Neuroimaging White Matter}

The increase of white matter hyperintensities (WMH) may represent underlying ischemia and impact upon the course of cognitive symptoms, which has been reported as a specific change of HF-related CI. The pathologically characteristics of WMH contains pale myelin sheath, loss of myelin sheath and axon, and mild gliosis. WMH can lead to cognitive decline and increase the risk of depression, anxiety, cerebrovascular events, dementia, and even death. These lesions usually present in small vessel diseases, which are considered to be the result of the destruction of the BBB caused by chronic cerebral hypoperfusion and the subsequent infiltration of plasma into white matter $(135,136)$. Brain MRI is a sensitive indicator of cerebrovascular disease and could use to image patients with HF with CI as it can reveal a number of asymptomatic findings, including $\mathrm{WMH}$. Beer et al. found that left medial temporal lobe atrophy and deep WMH detected by MRI showed a negative correlation with cognitive scores in patients with HF compared with healthy controls (137). The population-based LIFE-Adult Study quantitated white matter lesions in 2,490 participants and found that the prevalence was independently associated with WML (OR 2.8, 95\% CI 1.2-6.5), which was associated with cognitive dysfunction (138). Further, the longer duration of HF independently predicted WML while the duration of hypertension not.

Diffusion tensor imaging (DTI) reflects the integrity of the fiber bundle by detecting the anisotropy and degree of the water molecule diffusion in cerebral white matter fibers, which clearly display the direction and distribution of intracranial white matter fiber bundles after post-product. Kumar et al. found that the axial and radial diffusion was significantly increased and mainly existed in autonomous, analgesic, emotional, and cognitive parts in patients with HF than that in health controls, suggesting that the axon integrity and myelin were injured in patients with HF (139).

\section{Gray Matter}

The majority of imaging studies in CI have used MRI to investigate changes in gray matter structure. Almeida et al. compared the brain gray matter reduction using MRI and emotional changes between patients with chronic HF and healthy controls (140). It has demonstrated that the prevalence of depression and anxiety was much higher in patients with HF compared with that in healthy controls. Of note, gray matter loss mostly in particular parts of the brain with motional regulation, such as left and right thalamus, left caudate nucleus, left and right posterior cingulate gyrus, left and right parahippocampal gyrus, left upper middle temporal gyrus, and right lower parietal lobe.

\section{Brain Atrophy}

Studies have shown that half of patients with chronic HF has cortical brain atrophy exists, which is 10-flod higher than that in the control group $(31,91)$. With the advancement of imaging technologies, the detrimental effects of $\mathrm{HF}$ on CI have also been demonstrated with structural alterations of brain. The COGNITION.MATTERS-HF prospective cohort study quantified the concurring dynamics affecting cognitive functions in 148 patients with mild chronic HF and found that cognitive function remained stable with "intensity of attention" as the only domain declining over 3 years (141). Moreover, in patients with $\mathrm{HF}$, the markedly reductions of hippocampal volume observed at baseline was more related to impaired cognitive function, while the total brain volume and the load of white matter change within the limits of normal aging.

\section{Functional Brain Changes in Neuroimaging}

The use of single photon emission computed tomography (SPECT) enables to detect the distribution of radionuclides in the body. It is widely utilized due to its great value of diagnosis for early metabolic disorder in various diseases. Alves et al. found that the regional cerebral blood flow reductions in patients with HF using SPECT was similar to the regional glucose metabolism disorder in patients with CI by positron emission tomography, which support to a view that congestion dysfunction brain changes of congestion dysfunction may develop in patients with HF, possibly as a consequence of chronic cerebral blood flow hypoperfusion (142). Recently, a prospectively study enrolled 102 patients with HF and 15 healthy controls who underwent gated 99mTc-sestamibi SPECT and found that cerebral metabolism in the whole brain was reduced, especially hippocampus and para-hippocampus areas in patients with HF, while the cerebral metabolism maintained in frontal areas due to its higher sensitivity and self-regulation (143).

Functional MRI (fMRI) is a technique highlighting regional patterns of brain activation based on little change of the deoxy/oxy-hemoglobin ratio (144). Once the neuronal activity is enhanced, the blood flow through the cortex functional region significantly increased, which results a change of deoxy/oxyhemoglobin ratio. This ratio, due to the different magnetic properties of hemoglobin states, can be measured through MRI and reconstructed in the form of blood oxygenation leveldependent signal. Hence, fMRI has been widely used to describe the characteristics cerebral function and functional networks in CI and its related diseases. Several studies have shown the extensive activity reduction in the brain of patients with diabetes. 


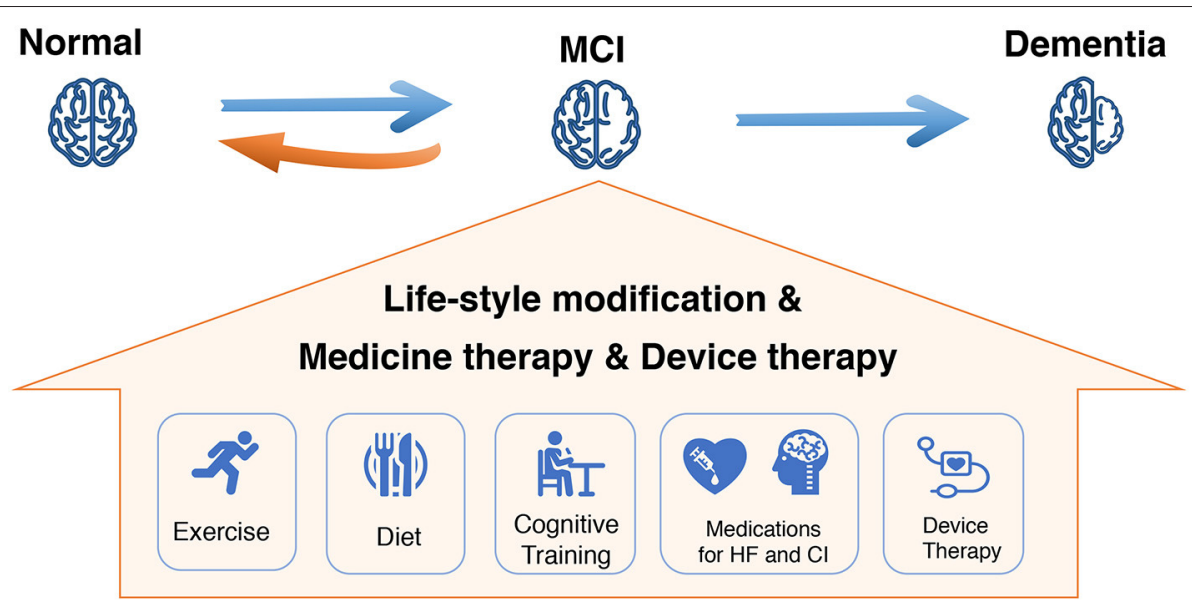

FIGURE 4 | Comprehensive management for mild $\mathrm{Cl}(\mathrm{MCl})$ in $\mathrm{HF}$ to halt disease progression. $\mathrm{MCl}$, mild cognitive impairment; $\mathrm{HF}$, heart failure.

However, fMRI is rarely used in patients with HF and CI clinically and data specific for HF are currently lacking.

\section{PREVENTION AND POTENTIAL THERAPEUTIC OPTIONS FOR CI IN HF}

Improving and maintaining cardiac function should be the primary strategy for treatment of CI in patients with HF, which would have a positive impact on brain function (Figure 4). Although clinical guidelines in HF have recently begun to emphasize the importance of $\mathrm{CI}$ in $\mathrm{HF}$, few recommendations are available to guide clinicians about how to approach $\mathrm{CI}$ in patients with HF. Contemporary HF therapies may improve or aggravate cognitive decline (Table 2). On the other hand, therapy for CI may also have cardiovascular side effects, which may in turn affect the treatment of HF. Furthermore, research are undergoing to develop novel potential therapeutic targets for $\mathrm{CI}$ and $\mathrm{HF}$ (Table 3).

\section{Contemporary Medical Therapies Effect of HF Medical Therapy on Cl Sodium Glucose Co-Transporter 2 Inhibitor}

The novel antidiabetic agent, sodium glucose co-transporter 2 (SGLT2) inhibitor, is essential for overcoming the burden of diabetic and have beneficial cardiovascular and renal effects, especially in improving the prognosis of HF, which supports it as a foundational therapy for HF $(153,154)$. Evidence have shown SGLT2 inhibitor to limit or slow down brain pathology in CI among patients with diabetes. Animal studies indicated that SGLT2 significantly ameliorated cognitive decline in type 2 diabetic mice $(152,155)$. A recent large propensity score-matched population-based study demonstrated that patients treated with SGLT2 inhibitors were associated with lower risks of dementia compared with when treated with DPP4 inhibitors (148). Simone et al. also found that cognitive status did not change significantly during the 12 months of treatment of SGLT2 inhibitor (156). However, whether the SGLT2 inhibitor could reduce incidence of cognitive or improve the cognitive dysfunction in HF is not known and requires further confirmation.

\section{Angiotensin Receptor Neprilysin Inhibitor}

Angiotensin receptor neprilysin inhibitors (ARNIs) significantly improve the clinical outcome of patients with HFrEF as shown in PARADIGM-HF which compared the angiotensin receptor neprilysin inhibitor (ARNI) (sacubitril/valsartan) with angiotensin converting enzyme inhibitor (ACEI) (enalapril). As neprilysin is one of enzymes clearing $A \beta$ peptides from the brain, in theory, inhibition of neprilysin may reduce $A \beta$ degradation and accelerate its accumulation (145). Besides, inhibition of neprilysin increases bradykinin levels, which directly interacts with $A \beta 1-42$ aggregates to generate $A \beta$ plaques. Hence, there is a concern about how neprilysin inhibitor may cause cognitive decline in patients treated with ARNI. However, large scale randomized controlled trials, such as PARADIGM$\mathrm{HF}$, confirm that there is no adverse effect of ARNI on CI $(146,147)$. A possible cause may be that cognitive decline in $\mathrm{HF}$ is not wholly related to Alzheimer's type pathology and may also be associated with declining cardiac function and vascular abnormalities. Therefore, the long-term ARNI treatment, by improving cardiovascular function and preventing hospitalization, may have a positive effect on cognitive function in patients with HF. Further, a study, PERSPECTIVE (NCT 02884206), is undergoing to explicitly focused on whether ARNNI will lead to CI in populations with HFpEF. This study is expected to be completed in March 2022.

\section{Angiotensin Converting Enzyme Inhibitor/Angiotensin II Receptor Blocker}

Angiotensin converting enzyme inhibitors (ACEIs)/angiotensin II receptor blockers (ARBs) have been shown to improve cognitive function in patients with HF by reducing the activity of sympathetic nervous system and improving cerebral blood flow (150). In a mouse model of $\mathrm{AD}$, the centrally active ACEI perindopril significantly reversed the CI, including the indices of immediate working memory and relatively long-term 
TABLE 2 | Summary of trials targeting medical treatment of cognitive impairment in heart failure (HF) (completed).

\begin{tabular}{|c|c|c|c|c|c|}
\hline Trial & $\begin{array}{c}\text { Year of } \\
\text { publication }\end{array}$ & Study design & Intervention & $\begin{array}{l}\text { Study population } \\
\text { (n) }\end{array}$ & Primary end point \\
\hline \multicolumn{6}{|l|}{ ACEIs/ARBs } \\
\hline $\begin{array}{l}\text { The antihypertensives and } \\
\text { vascular, endothelial and } \\
\text { cognitive function trial } \\
\text { (AVEC trial) (157) }\end{array}$ & 2012 & Randomized, controlled & $\begin{array}{l}\text { Candesartan vs. } \\
\text { lisinopril vs. } \\
\text { hydrochlorothiazide }\end{array}$ & $\begin{array}{l}\text { hypertension and } \\
\text { cognitive impairment } \\
\text { aged } \geq 60 \text { years (53) }\end{array}$ & $\begin{array}{l}\text { Changes in cognitive } \\
\text { assessment: making test } \\
\text { parts } A \text { and } B(T M T), \\
\text { Hopkins verbal learning } \\
\text { test-revised (HVLT), and } \\
\text { the digit span test. }\end{array}$ \\
\hline Soto et al. (151) & 2013 & Randomized, controlled & $\begin{array}{l}\text { ACEls vs. other } \\
\text { antihypertensive } \\
\text { drugs }\end{array}$ & $\begin{array}{l}\text { Older adults with } \\
\text { mild to moderate } \\
\text { Alzheimer's disease } \\
(616)\end{array}$ & Change in MMSE score. \\
\hline $\begin{array}{l}\text { Ginkgo evaluation of } \\
\text { memory study (GEMS) (158) }\end{array}$ & 2013 & $\begin{array}{l}\text { A post-hoc analysis of } \\
\text { the randomized } \\
\text { controlled GEMS trial. }\end{array}$ & $\begin{array}{l}\text { ACEls vs. diuretic } \\
\text { vs. ARB vs. } \\
\beta \text {-blocker vs. CCB }\end{array}$ & $\begin{array}{l}\text { Older adults aged } \\
\geq 75 \text { years with } \\
\text { normal cognition } \\
(1,928) \text { or } \mathrm{MCl}(320)\end{array}$ & Incidence of AD. \\
\hline Zuccalà et al. (150) & 2005 & $\begin{array}{l}\text { Observational, } \\
\text { retrospective }\end{array}$ & $\begin{array}{l}\text { With ACEls vs. } \\
\text { without ACEls }\end{array}$ & Heart failure $(1,220)$ & $\begin{array}{l}\text { The improvement of } \\
\text { cognitive performance }\end{array}$ \\
\hline
\end{tabular}

Change of systolic Candesartan improved in TMT-B $(P=0.008)$, blood pressure and the adjusted TMT, B-A which adjusts the test blood flow velocity for motor speed $(P=0.012)$, and the recognition portion of the HVLT $(P=0.034)$. Blood pressure control levels and systolic blood pressure reductions were equivalent in all three groups.

The use of ACEls in older adults with $A D$ is associated with a slowest rate of decline in MMSE score independent of hypertension.

ACEI, ARB, or diuretic use was associated with reduced risk of $A D$ among patients with normal cognition or $\mathrm{MCl}$.

Cognitive performance improved in 30\% of participants started ACEls, but only in $22 \%$ of remaining patients $(P=0.001)$. Use of ACEls among patients with heart failure was associated with improving cognition (odds ratio $=1.57 ; 95 \% \mathrm{Cl} 1.18-2.08$ ) in the multivariable regression modeling, independently of baseline or discharge blood pressure levels. The probability of improving cognitive performance was higher for dosages above the median values compared with lower doses (odds ratios $=1.90$ and $1.42 ; P$ for trend $=0.001$, and increased with duration of treatment (odds ratios for the lower, middle, and upper tertiles $=$ $1.25,1.34$, and 1.59; $P$ for trend $=0.007$ )

In cognitively normal older adults, ARB use was associated with a lower rate of global $A \beta$ accumulation over time compared to ACE-I users. The rates of amyloid- $\beta$ accumulation had no difference between ARBs or ACEls in amyloid-positive participants with $\mathrm{AD}$ dementia or $\mathrm{MCl}$. 


\begin{tabular}{|c|c|c|c|c|c|c|c|}
\hline Trial & $\begin{array}{c}\text { Year of } \\
\text { publication }\end{array}$ & Study design & Intervention & $\begin{array}{l}\text { Study population } \\
\text { (n) }\end{array}$ & Primary end point & $\begin{array}{l}\text { Secondary end } \\
\text { points }\end{array}$ & Results \\
\hline Hajjar et al. (159) & 2020 & Randomized, controlled & $\begin{array}{l}\text { Candesartan vs. } \\
\text { lisinopril }\end{array}$ & $\begin{array}{l}\text { hypertension and } \\
\text { mild cognitive } \\
\text { impairment aged } 55 \\
\text { years or older (141) }\end{array}$ & $\begin{array}{l}\text { Change in executive } \\
\text { function (measured using } \\
\text { the trail making test, } \\
\text { executive abilities: measures } \\
\text { and instruments for } \\
\text { neurobehavioral evaluation } \\
\text { and research tool) }\end{array}$ & $\begin{array}{l}\text { Change in episodic } \\
\text { memory (measured } \\
\text { using the Hopkins } \\
\text { verbal learning } \\
\text { test-revised) and } \\
\text { microvascular brain } \\
\text { injury reflected by } \\
\text { MRI of white matter } \\
\text { lesions. }\end{array}$ & $\begin{array}{l}\text { Candesartan was superior to lisinopril on the } \\
\text { executive function measured by Trail Making } \\
\text { Test Part B [effect size (ES) }=-12.8 \text { ( } 95 \% \mathrm{Cl} \text {, } \\
-22.5 \text { to }-3.1) \text { ] but not executive abilities: } \\
\text { measures and instruments for neurobehavioral } \\
\text { evaluation and research score. Candesartan } \\
\text { was also superior to lisinopril on the secondary } \\
\text { outcome of Hopkins Verbal Learning } \\
\text { Test-Revised delayed recall [ES }=0.4(95 \% \mathrm{Cl} \text {, } \\
0.02-0.8) \text { ] and retention [ES }=5.1(95 \% \\
\mathrm{Cl}, 0.7-9.5) \text { ]. }\end{array}$ \\
\hline \multicolumn{8}{|l|}{$\beta$-blockers } \\
\hline Holm et al. (162) & 2020 & Randomized, controlled, & $\begin{array}{l}\text { With } \beta \text {-blockers vs. } \\
\text { without } \beta \text {-blockers }\end{array}$ & $\begin{array}{l}\text { General population } \\
\text { treated with } \\
\beta \text {-blockers }(18,063)\end{array}$ & $\begin{array}{l}\text { Incidence of dementia } \\
\text { (developing vascular } \\
\text { dementia, all-cause, } \\
\text { Alzheimer's and mixed } \\
\text { dementia) }\end{array}$ & - & $\begin{array}{l}\beta \text {-blocker therapy was independently } \\
\text { associated with increased risk of developing } \\
\text { vascular dementia, regardless of confounding } \\
\text { factors (HR: } 1.72,95 \% \mathrm{Cl} 1.01-3.78 ; P= \\
0.048 \text { ). Conversely, treatment with } \beta \text {-blockers } \\
\text { was not associated with increased risk of } \\
\text { all-cause, Alzheimer's and mixed dementia }\end{array}$ \\
\hline \multicolumn{8}{|l|}{ ARNI } \\
\hline PARADIGM-HF. (146) & 2017 & Randomized, controlled & $\begin{array}{l}\text { Sacubitril/valsartan } \\
97 / 103 \mathrm{mg} \text { bid vs. } \\
\text { enalapril } 10 \mathrm{mg} \text { bid } \\
\text { in a } 1: 1 \text { ratio }\end{array}$ & $\begin{array}{l}\text { Symptomatic HFrEF } \\
(8,399)\end{array}$ & $\begin{array}{l}\text { Relevant cognition- and } \\
\text { memory-related adverse } \\
\text { event (AE) reports }\end{array}$ & - & $\begin{array}{l}\text { The incidence of dementia-related AEs in } \\
\text { patients treated with sacubitril/valsartan was } \\
\text { similar to that in patients treated with enalapril. }\end{array}$ \\
\hline \multicolumn{8}{|l|}{ SGLT2 inhibitor } \\
\hline Simone et al. (156) & 2018 & Randomized, controlled & $\begin{array}{l}\text { Incretins vs. SGLT2 } \\
\text { inhibitor }\end{array}$ & $\begin{array}{l}\text { Elderly patients with } \\
\text { type } 2 \text { diabetes } \\
\text { mellitus (39) }\end{array}$ & $\begin{array}{l}\text { Change of cognitive } \\
\text { performance with the } \\
\text { attentive matrices test, the } \\
\text { verbal fluency test and the } \\
\text { Babcock story recall test. }\end{array}$ & Metabolic outcomes. & $\begin{array}{l}\text { Cognitive status did not change significantly } \\
\text { during the } 12 \text { months of treatment in SGLT2 } \\
\text { inhibitor group or incretins group. SGLT2 } \\
\text { inhibitor resulted in a reduction in weight, in } \\
\text { BMI, and an increase in high-density } \\
\text { lipoprotein cholesterol. }\end{array}$ \\
\hline Mui et al. (148) & 2021 & $\begin{array}{l}\text { Retrospective, } \\
\text { territory-wide cohort } \\
\text { study }\end{array}$ & SGLT2I vs. DPP4I & $\begin{array}{l}\text { Type } 2 \text { diabetes } \\
\text { mellitus patients } \\
(39,828)\end{array}$ & $\begin{array}{l}\text { New-onset dementia, } \\
\text { Alzheimer's, and } \\
\text { Parkinson's. }\end{array}$ & $\begin{array}{l}\text { All-cause, } \\
\text { cardiovascular, and } \\
\text { cerebrovascular } \\
\text { mortality. }\end{array}$ & $\begin{array}{l}\text { SGLT2I users had lower incidences of } \\
\text { dementia, Alzheimer's, Parkinson's disease, } \\
\text { all-cause, cerebrovascular, and } \\
\text { cardiovascular mortality. SGLT2I use was } \\
\text { associated with lower risks of dementia, } \\
\text { Parkinson's, all-cause, cardiovascular, and } \\
\text { cerebrovascular mortality. }\end{array}$ \\
\hline
\end{tabular}

A , amyloid- $\beta$; ACEIs, angiotensin converting enzyme inhibitors; AD, Alzheimer's disease; ARNI, angiotensin receptor neprilysin inhibitor; ARBs, angiotensin II receptor blockers; MCl, mild Cl; MRIs, magnetic resonance images; SGLT2, sodium glucose co-transporter 2 . 


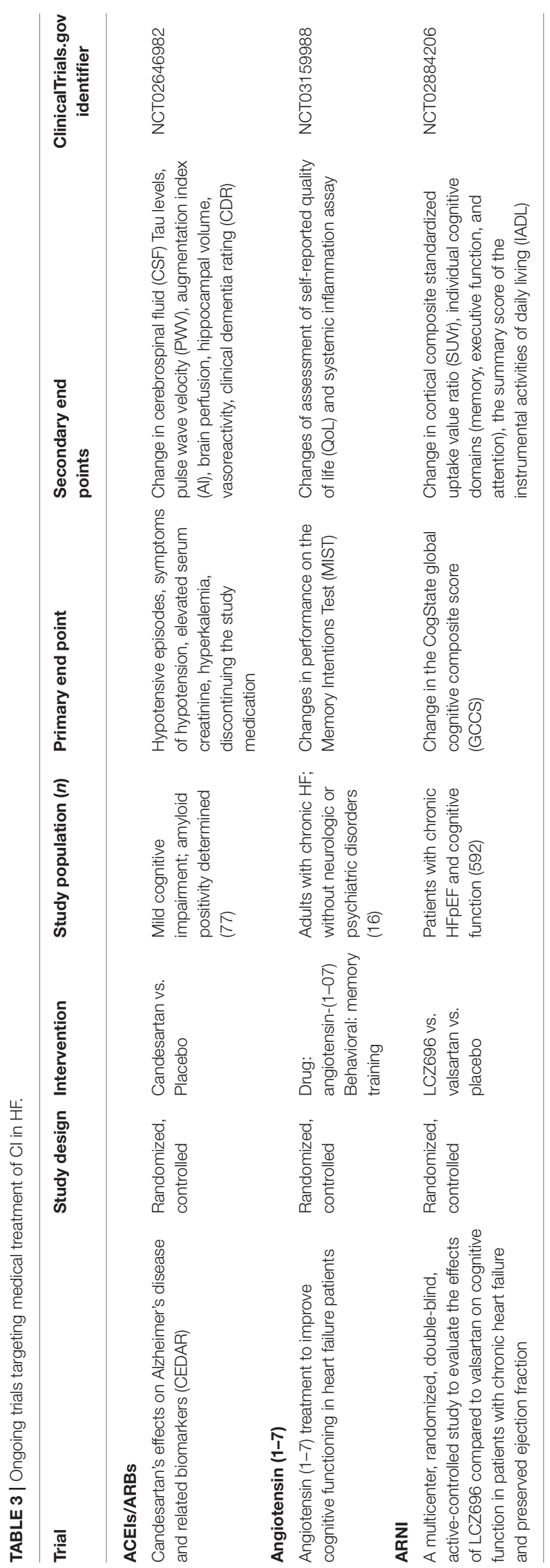

recognition memory (149). In elderly patients with hypertension and CI, studies have indicated that ACEIs and ARBs could improve the cognitive function and were associated with reduced risk of $\mathrm{AD}$ (151, 157-159). Recently, research demonstrated that $\mathrm{ARBs}$ had a stronger protection against memory decline than ACEIs through its potential benefits on the inhibition of $A \beta$ accumulation in the cortex (160).

\section{$\beta$-Blockers}

Findings of $\beta$-blockers to improve CI are heterogeneous, and some are even controversial. $\beta$-blockers may reduce the incidence of CI through the control of blood pressure. It has been first reported in JAMA in 1986 that $\beta$-blockers may lead to depression, which is a cause of CI. However, another study showed that there was no correlation between $\beta$-blockers and depression the next year. A meta-analysis indicated $\beta$-blockers were related to the occurrence of vascular dementia $(161,162)$. Thus, further investigations are warranted to identify the specific relationship between $\beta$-blockers and $\mathrm{CI}$.

\section{Mineralocorticoid Receptor Antagonists}

Mineralocorticoid receptors are ubiquitously expressed in limbic brain structures such as the hippocampus, amygdala, and prefrontal cortex. Findings showed that mineralocorticoid receptor antagonists (MRAs) decreased verbal learning, verbal memory, and visuospatial memory in adult population and impaired verbal memory and executive function in young depressed patients. However, MRAs improved verbal learning and visuospatial memory in elderly depressed patients. Thus far, the relevant research of MRAs and CI is relatively limited, and the impact of MRAs on CI is still controversial (163).

\section{Effect of Cl Medical Therapy on HF}

Virtually all clinical trials of HF therapy have excluded patients with CI or dementia. There is limited data pertaining to the treatment for CI in HF. As a result, current guidelines are unable to provide evidence-based recommendations for diagnosis and treatment of patients with CI in routine clinical practice (164). Acetylcholinesterase inhibitors and memantine are considered as the first-line therapy for CI due to the benefit of concentration and memory. A position paper from the Study Group on Heart and Brain Interaction of the Heart Failure Association mentioned the favorable side effect profile for $\mathrm{CI}$ and the potential cardiovascular adverse events. For acetylcholinesterase inhibitors co-treated with $\beta$-blockers, digoxin, amiodarone, and calcium channel blockers may increase the risk for syncope or heart block. Dizziness, hypertension, angina, bradycardia, and HF may be observed in patients treated with memantine (165, 166).

\section{Novel Therapeutic Targets}

Angiotensin-converting enzyme 2 (ACE2), angiotensin-(1-7) [Ang-(1-7)], and Mas have been identified as a new component of RAS, which constitute ACE2-Ang-(1-7)-Mas axis (167). Recently, Ang-(1-7) has showed to reverse HF-related CI in animal experiment. Ang-(1-7) is mainly produced by the hydrolysis of Ang II and the ligand for the Mas receptor. MAS is highly 
expressed in the hippocampus, a brain region related to memory function. Thus, the activation of Mas by Ang-(1-7) may play a protective role in brain. Hay et al. found that following 3 weeks treatment with systemic Ang-(1-7), the HF mice novel object recognition discrimination ratios were significantly better than the performance of mice with HF treated with saline (168). Ang-(1-7) also improved spatial memory in mice with HF without effect on cardiac function. Besides, 3 weeks of Ang(1-7) treatment in the mice with HF resulted in a significant increase in plasma IL-1a, G-CSF, IL-16, and sICAM, which have been shown a neuroprotection in animal models of head injury or brain ischemia (169). The latest study demonstrated a novel glycosylated Ang-(1-7) peptide, Ang-1-6-O-Ser-Glc- $\mathrm{NH}_{2}$ (PNA5), which has greater brain penetration compared with the native Ang-(1-7) peptide in HF mice model. Moreover, after treatment with subcutaneous injection $1.0 / \mathrm{mg} / \mathrm{kg}$ for 3 weeks, PNA5 activation of the Mas receptor reversed object recognition impairment in mice with $\mathrm{HF}$ and rescued spatial memory impairment. PNA5 treatment also decreased circulating proinflammatory cytokine, such as TNF- $\alpha$, IL-7, and granulocyte cell-stimulating factor serum levels, while increasing that of the anti-inflammatory cytokine IL-10.

As an important inflammatory factor mediating the occurrence of CI in HF, TNF- $\alpha$ is also a potential therapeutic target. TNF- $\alpha$ inhibitor Etanercept improve cognitive function by increasing the density of dendritic spines in frontal and parietal cortex (76). In addition, Lidington et al. found that a TNF- $\alpha$ negative regulator, cystic fibrosis transmembrane conductance regulator (CFTR) may be a novel therapeutics target for CI in HF. By emulating the key features of HF-related $\mathrm{CI}$, including reduced $\mathrm{CBF}$ and compromised neurologic function in mouse models, CFTR corrector compounds (C18) normalize pathological alterations in cerebral artery CFTR expression, vascular reactivity, and cerebral perfusion without affecting systemic hemodynamic parameters (170). Therefore, CFTR therapeutics may be a novel target to manage CI in HF.

\section{Non-pharmacologic Approaches for $\mathrm{Cl}$ in $\mathrm{HF}$}

Life-Style Modification Physical Activity and Exercise

Studies indicated that the modification of lifestyle, including exercise and diet, can potentially improve cognition in patients with HF. Higher daily steps per day predicted better cognitive function and greater subcortical volume, with specific effects for the thalamus and ventral diencephalon (171). Redwine et al. also showed a greater MoCA score increases in patients with HF with Tai Chi or resistance band exercise compared to treatment as usual. Recently, Vellone et al. found that worse CI was independently associated with lower 6MWT scores. Of note, exercise capacity was associated with various cognitive domain, including visuospatial/executive, naming, attention, language, and orientation (19). Diet modification, such as lowsalt diet, Mediterranean diet, and high-fiber diet, is also a feasible approach to preserving cognitive function and reducing risk of dementia. Several observational studies reported a protective association between certain nutrients (e.g., folate, flavonoids, vitamin D, and certain lipids) or food groups (e.g., seafood, vegetables, and fruit) and cognitive outcomes in older adults. A large randomized controlled trial further demonstrated a 2-year multidomain intervention of diet, exercise, cognitive training, and vascular risk monitoring could improve or maintain cognitive function in at-risk elderly people from the general population (172).

\section{Device Therapy}

Device therapy of HF has been reported contribute to cognitive improvement by improving cardiac output. Patients with moderate to severe HF enhanced cognitive outcomes within 3 months of cardiac resynchronization therapy (CRT) due to the improved left ventricular ejection fraction (LVEF) in response to CRT (173). Patients with improved LVEF showed better outcomes on measures of executive functioning, global cognition, and visuospatial functioning. Similarly, Zimpfer et al. indicated that successful ventricular assist devices implantation contributes to cognitive improvement by increasing cerebral blood flow in patients with advanced HF (174). Besides, as a common comorbidity of HF, AF exacerbates cognitive dysfunction and cerebral perfusion in patients with HF (94). Recently, a prospective case-control study assessed changes in cognitive function in 308 patients treated with AF catheter ablation and 50 medically managed controls, finding a significant improvement in cognitive function at 3 months and 1 year after ablation but not in the control group (175). This result supported that ablation may facilitate cognitive recovery from cerebral hypoperfusion by restoring sinus rhythm.

\section{KNOWLEDGE GAPS AND AREAS FOR FUTURE RESEARCH}

The prevalent $\mathrm{CI}$ in patients with HF bring a greater burden to the poor outcome and worsening quality of life. Even though great efforts sought to characterize the detrimental issue the with increasing awareness and advancement of the diagnostic tools, knowledge gaps still exist in this field. First, more prospective data on the role of HF in cognitive decline await future detailed investigations. Specifically, well-designed longitudinal studies with longer follow-up are warranted to illustrate the time cure in regard of: (1) the precise progression of cognitive decline from normal to dementia in patients with HF; and (2) the deleterious effect of varying degree of CI on survivor time and clinical course of HF. Additionally, comprehensive evaluations, including treatment effectiveness, compliance, caregiver burden and frailty, should be considered. Second, further research deserves to expound the contributory mechanisms involved in the pathophysiology of CI in HF to deepen understanding of heart-brain interaction. Third, systematic assessment of CI in HF with multiple imaging and neuropsychiatric approach, risk stratifications with specific biomarker profiles, and prediction models are expected to provide more prognostic information and guide therapy decisions. Fourth, despite the growing knowledge about the mutual malignant impact of HF and CI, little is known on promising targets for novel therapeutic interventions. 
In the future, research priorities outlined above will attract far more attentions in HF-CI interconnectivity. The availability of novel techniques, emerging and existing (repurposed) therapies, computational modeling and novel insights will help address these knowledge gaps.

\section{CONCLUSIONS}

Heart failure (HF) and CI are increasing in prevalence and, when present together, are associated with significant mortality and morbidity. The underlying mechanisms of the link between cardiac dysfunction and brain pathologies in HF condition are still largely elusive. While patients with HF with dementia have great difficulties in daily life and are heavily dependent on caregivers, patients with CI are more independent. Routine screening of CI is needed in HF, even from using a simple tool like MoCA, thereby improving the efficiency of HF management. In patients with $\mathrm{HF}$ and $\mathrm{CI}$, lifestyle change and risk factor control, standard HF therapy, and appropriate medication for CI should be standard of management. Further studies are needed not only to unravel the bidirectional pathology of the heart and cognition, but also to provide more efficient interventions in the brain following HF-associated conditions. Close collaboration between the HF and neurology specialists is essential in the

\section{REFERENCES}

1. Patnode CD, Perdue LA, Rossom RC, Rushkin MC, Redmond N, Thomas $\mathrm{RG}$, et al. Screening for cognitive impairment in older adults: updated evidence report and systematic review for the US preventive services task force. JAMA. (2020) 323:764-85. doi: 10.1001/jama.2019.22258

2. Virani SS, Alonso A, Aparicio HJ, Benjamin EJ, Bittencourt MS, Callaway CW, et al. Heart disease and stroke statistics-2021 update: a report from the American Heart Association. Circulation. (2021) 143:e254743. doi: 10.1161/CIR.0000000000000950

3. Havakuk O, King KS, Grazette L, Yoon AJ, Fong M, Bregman N, et al. Heart failure-induced brain injury. J Am Coll Cardiol. (2017) 69:160916. doi: 10.1016/j.jacc.2017.01.022

4. Bueno H, Moura B, Lancellotti P, Bauersachs J. The year in cardiovascular medicine 2020: heart failure and cardiomyopathies. Eur Heart J. (2021) 42:657-70. doi: 10.1093/eurheartj/ehaa1061

5. Metra M, Teerlink JR. Heart failure. Lancet. (2017) 390:198195. doi: 10.1016/S0140-6736(17)31071-1

6. Owens DK, Davidson KW, Krist AH, Barry MJ, Cabana M, Caughey AB, et al. Screening for cognitive impairment in older adults: US preventive services task force recommendation statement. JAMA. (2020) 323:75763. doi: 10.1001/jama.2020.0435

7. Dunne RA, Aarsland D, O’Brien JT, Ballard C, Banerjee S, Fox NC, et al. Mild cognitive impairment: the Manchester consensus. Age Ageing. (2021) 50:72-80. doi: 10.1093/ageing/afaa228

8. Arvanitakis Z, Shah RC, Bennett DA. Diagnosis and management of dementia: review. JAMA. (2019) 322:1589-99. doi: 10.1001/jama.2019.4782

9. Cameron J, Worrall-Carter L, Page K, Riegel B, Lo SK, Stewart S. Does cognitive impairment predict poor self-care in patients with heart failure? Eur J Heart Fail. (2010) 12:508-15. doi: 10.1093/eurjhf/hfq042

10. Zuccalà G, Marzetti E, Cesari M, Lo Monaco MR, Antonica L, Cocchi A, et al. Correlates of cognitive impairment among patients with heart failure: results of a multicenter survey. Am J Med. (2005) 118:496502. doi: 10.1016/j.amjmed.2005.01.030

11. Dong Y, Teo SY, Kang K, Tan M, Ling LH, Yeo PSD, et al. Cognitive impairment in Asian patients with heart failure: prevalence, biomarkers, early recognition and appropriate management of these patients. Future research to develop a consensus management guideline for patients with $\mathrm{HF}$ and CI, which is not yet available, is warranted.

\section{AUTHOR CONTRIBUTIONS}

MYang and DS searched and selected the references and wrote the first draft of the review. YW and MYan contributed toward literature review and interpretation of the manuscript. JZ and JR helped to determine the content and structure of the review and contributed to the writing and revision of the manuscript. All authors approved the final version of the paper.

\section{FUNDING}

This study was supported by the National Natural Science Foundation of China (81770359 to JR), Beijing Health Technologies Promotion Program (BHTPP202004 to JR), Open Project Fund of State Key Laboratory of Molecular Developmental Biology of China (2021-MDB-KF-18 to JR), and Elite Medical Professionals Project of China-Japan Friendship Hospital (ZRJY2021-BJ01 to JR). clinical correlates, and outcomes. Eur J Heart Fail. (2019) 21:68890. doi: 10.1002/ejhf.1442

12. Busse A, Hensel A, Gühne U, Angermeyer MC, Riedel-Heller SG. Mild cognitive impairment: long-term course of four clinical subtypes. Neurology. (2006) 67:2176-85. doi: 10.1212/01.wnl.0000249117.23318.e1

13. Di Carlo, Lamassa $M$, Baldereschi $M$, Inzitari $M$, Scafato $E$, Farchi G, et al. CIND and MCI in the Italian elderly: frequency, vascular risk factors, progression to dementia. Neurology. (2007) 68:1909-16. doi: 10.1212/01.wnl.0000263132.99055.0d

14. Plassman BL, Langa KM, Fisher GG, Heeringa SG, Weir $\mathrm{DR}$, Ofstedal $\mathrm{MB}$, et al. Prevalence of cognitive impairment without dementia in the United States. Ann Intern Med. (2008) 148:427-34. doi: 10.7326/0003-4819-148-6-200803180-00005

15. Lopez OL, Jagust WJ, DeKosky ST, Becker JT, Fitzpatrick A, Dulberg C, et al. Prevalence and classification of mild cognitive impairment in the cardiovascular health study cognition study: part 1. Arch Neurol. (2003) 60:1385-9. doi: 10.1001/archneur.60.10.1385

16. Petersen RC, Smith GE, Waring SC, Ivnik RJ, Tangalos EG, Kokmen E. Mild cognitive impairment: clinical characterization and outcome. Arch Neurol. (1999) 56:303-8. doi: 10.1001/archneur.56.3.303

17. Farias ST, Mungas D, Reed BR, Harvey D, DeCarli C. Progression of mild cognitive impairment to dementia in clinic- vs. community-based cohorts. Arch Neurol. (2009) 66:1151-7. doi: 10.1001/archneurol.2009.106

18. Huynh QL, Negishi K, De Pasquale CG, Hare JL, Leung D, Stanton $\mathrm{T}$, et al. Cognitive domains and postdischarge outcomes in hospitalized patients with heart failure. Circ Heart Fail. (2019) 12:e006086. doi: 10.1161/CIRCHEARTFAILURE.119.006086

19. Vellone E, Chialà O, Boyne J, Klompstra L, Evangelista LS, Back M, et al. Cognitive impairment in patients with heart failure: an international study. ESC Heart Fail. (2020) 7:46-53. doi: 10.1002/ehf2.12542

20. Agarwal KS, Kazim R, Xu J, Borson S, Taffet GE. Unrecognized cognitive impairment and its effect on heart failure readmissions of elderly adults. $J$ Am Geriatr Soc. (2016) 64:2296-301. doi: 10.1111/jgs.14471

21. Grubb NR, Simpson C, Fox KA. Memory function in patients with stable, moderate to severe cardiac failure. Am Heart J. (2000) 140:E15. doi: $10.1067 / \mathrm{mhj} .2000 .106647$ 
22. Schall RR, Petrucci RJ, Brozena SC, Cavarocchi NC, Jessup M. Cognitive function in patients with symptomatic dilated cardiomyopathy before and after cardiac transplantation. J Am Coll Cardiol. (1989) 14:166672. doi: 10.1016/0735-1097(89)90013-2

23. Gure TR, Blaum CS, Giordani B, Koelling TM, Galecki A, Pressler SJ, et al. Prevalence of cognitive impairment in older adults with heart failure. J Am Geriatr Soc. (2012) 60:1724-9. doi: 10.1111/j.1532-5415.2012.04097.x

24. Yaffe K, Vittinghoff E, Pletcher MJ, Hoang TD, Launer LJ, Whitmer R, et al. Early adult to midlife cardiovascular risk factors and cognitive function. Circulation. (2014) 129:15607. doi: 10.1161/CIRCULATIONAHA.113.004798

25. Gallagher R, Sullivan A, Burke R, Hales S, Gillies G, Cameron J, et al. Mild cognitive impairment, screening, and patient perceptions in heart failure patients. J Card Fail. (2013) 19:641-6. doi: 10.1016/j.cardfail.2013.08.001

26. Warraich HJ, Kitzman DW, Whellan DJ, Duncan PW, Mentz RJ, Pastva $\mathrm{AM}$, et al. Physical function, frailty, cognition, depression, and quality of life in hospitalized adults $\geq 60$ years with acute decompensated heart failure with preserved versus reduced ejection fraction. Circ Heart Fail. (2018) 11:e005254. doi: 10.1161/CIRCHEARTFAILURE.118.005254

27. Hammond CA, Blades NJ, Chaudhry SI, Dodson JA, Longstreth WT, Jr., et al. Long-term cognitive decline after newly diagnosed heart failure: longitudinal analysis in the CHS (cardiovascular health study). Circ Heart Fail. (2018) 11:e004476. doi: 10.1161/CIRCHEARTFAILURE.117.004476

28. Jutkowitz E, MacLehose RF, Gaugler JE, Dowd B, Kuntz KM, Kane RL. Risk factors associated with cognitive, functional, and behavioral trajectories of newly diagnosed dementia patients. J Gerontol A Biol Sci Med Sci. (2017) 72:251-8. doi: 10.1093/gerona/glw079

29. Ampadu J, Morley JE. Heart failure and cognitive dysfunction. Int J Cardiol. (2015) 178:12-23. doi: 10.1016/j.ijcard.2014.10.087

30. Faulkner KM, Dickson VV, Fletcher J, Katz SD, Chang PP, Gottesman RF, et al. Factors associated with cognitive impairment in heart failure with preserved ejection fraction. J Cardiovasc Nurs. (2020) 37:1730. doi: 10.1097/JCN.0000000000000711

31. Frey A, Sell R, Homola GA, Malsch C, Kraft P, Gunreben I, et al. Cognitive deficits and related brain lesions in patients with chronic heart failure. JACC Heart Fail. (2018) 6:583-92. doi: 10.1016/j.jchf.2018.03.010

32. Ichijo Y, Kono S, Yoshihisa A, Misaka T, Kaneshiro T, Oikawa M, et al. Impaired frontal brain activity in patients with heart failure assessed by near-infrared spectroscopy. J Am Heart Assoc. (2020) 9:e014564. doi: 10.1161/JAHA.119.014564

33. Sacre JW, Ball J, Wong C, Chan YK, Stewart S, Kingwell BA, et al. Mild cognitive impairment is associated with subclinical diastolic dysfunction in patients with chronic heart disease. Eur Heart J Cardiovasc Imaging. (2018) 19:285-92. doi: 10.1093/ehjci/jex169

34. Matsue Y, Kamiya K, Saito H, Saito K, Ogasahara Y. Maekawa E, et al. Prevalence and prognostic impact of the coexistence of multiple frailty domains in elderly patients with heart failure: the FRAGILE-HF cohort study. Eur J Heart Fail. (2020) 22:2112-9. doi: 10.1002/ejhf.1926

35. Patel A, Parikh R, Howell EH, Hsich E, Landers SH, Gorodeski EZ. Mini-cog performance: novel marker of post discharge risk among patients hospitalized for heart failure. Circ Heart Fail. (2015) 8:816. doi: 10.1161/CIRCHEARTFAILURE.114.001438

36. Mamas MA, Sperrin M, Watson MC, Coutts A, Wilde K, Burton C, et al. Do patients have worse outcomes in heart failure than in cancer? A primary care-based cohort study with 10-year follow-up in Scotland. Eur J Heart Fail. (2017) 19:1095-104. doi: 10.1002/ejhf.822

37. Kure CE, Rosenfeldt FL, Scholey AB, Pipingas A, Kaye DM, Bergin PJ, et al. Relationships among cognitive function and cerebral blood flow, oxidative stress, and inflammation in older heart failure patients. J Card Fail. (2016) 22:548-59. doi: 10.1016/j.cardfail.2016.03.006

38. Alosco ML, Spitznagel MB, van Dulmen $M$, Raz N, Cohen R, Sweet LH, et al. Cognitive function and treatment adherence in older adults with heart failure. Psychosom Med. (2012) 74:965-73. doi: 10.1097/PSY.0b013e318272ef2a

39. Lovell J, Pham T, Noaman SQ, Davis MC, Johnson M, Ibrahim JE. Self-management of heart failure in dementia and cognitive impairment: a systematic review BMC. Cardiovasc Disord. (2019) 19:99. doi: 10.1186/s12872-019-1077-4
40. Huynh QL, Whitmore K, Negishi K, DePasquale CG, Hare JL, Leung D, et al. Cognitive impairment as a determinant of response to management plans after heart failure admission. Eur J Heart Fail. (2021) 23:120514. doi: 10.1002/ejhf.2177

41. Ovsenik A, Podbregar M, Fabjan A. Cerebral blood flow impairment and cognitive decline in heart failure. Brain Behav. (2021) 11:e02176. doi: 10.1002/brb3.2176

42. Rajagopalan B, Raine AE, Cooper R, Ledingham JG. Changes in cerebral blood flow in patients with severe congestive cardiac failure before and after captopril treatment. Am J Med. (1984) 76:86-90. doi: 10.1016/0002-9343(84)90891-X

43. Petersen P, Kastrup J, Videbaek R, Boysen G. Cerebral blood flow before and after cardioversion of atrial fibrillation. J Cereb Blood Flow Metab. (1989) 9:422-5. doi: 10.1038/jcbfm.1989.62

44. Cornwell WK, III, Tarumi T, Aengevaeren VL, Ayers C, Divanji P, Fu Q, et al. Effect of pulsatile and nonpulsatile flow on cerebral perfusion in patients with left ventricular assist devices. J Heart Lung Transplant. (2014) 33:1295-303. doi: 10.1016/j.healun.2014.08.013

45. Gruhn N, Larsen FS, Boesgaard S, Knudsen GM, Mortensen SA, Thomsen G, et al. Cerebral blood flow in patients with chronic heart failure before and after heart transplantation. Stroke. (2001) 32:25303. doi: 10.1161/hs1101.098360

46. Choi BR, Kim JS, Yang YJ, Park KM, Lee CW, Kim YH, et al. Factors associated with decreased cerebral blood flow in congestive heart failure secondary to idiopathic dilated cardiomyopathy. Am J Cardiol. (2006) 97:1365-9. doi: 10.1016/j.amjcard.2005.11.059

47. Stöhr EJ, McDonnell BJ, Colombo PC, Willey JZ. CrossTalk proposal: Blood flow pulsatility in left ventricular assist device patients is essential to maintain normal brain physiology. J Physiol. (2019) 597:353-6. doi: 10.1113/JP276729

48. Zuccalà G, Cattel C, Manes-Gravina E, Di Niro MG, Cocchi A, Bernabei R. Left ventricular dysfunction: a clue to cognitive impairment in older patients with heart failure. J Neurol Neurosurg Psychiatry. (1997) 63:50912. doi: 10.1136/jnnp.63.4.509

49. Iadecola C. The neurovascular unit coming of age: a journey through neurovascular coupling in health and disease. Neuron. (2017) 96:1742. doi: 10.1016/j.neuron.2017.07.030

50. Roy B, Woo MA, Wang DJJ, Fonarow GC, Harper RM, Kumar R. Reduced regional cerebral blood flow in patients with heart failure. Eur J Heart Fail. (2017) 19:1294-302. doi: 10.1002/ejhf.874

51. Schuff N, Matsumoto S, Kmiecik J, Studholme C, Du A, Ezekiel F, et al. Cerebral blood flow in ischemic vascular dementia and Alzheimer's disease, measured by arterial spin-labeling magnetic resonance imaging. Alzheimers Dement. (2009) 5:454-62. doi: 10.1016/j.jalz.2009.04.1233

52. Jefferson AL, Tate DF, Poppas A, Brickman AM, Paul RH, Gunstad J, et al. Lower cardiac output is associated with greater white matter hyperintensities in older adults with cardiovascular disease. J Am Geriatr Soc. (2007) 55:10448. doi: 10.1111/j.1532-5415.2007.01226.x

53. Leech T, Apaijai N, Palee S, Higgins LA, Maneechote C, Chattipakorn $\mathrm{N}$, et al. Acute administration of metformin prior to cardiac ischemia/reperfusion injury protects brain injury. Eur J Pharmacol. (2020) 885:173418. doi: 10.1016/j.ejphar.2020.173418

54. Ogunshola OO, Al-Ahmad A. HIF-1 at the blood-brain barrier: a mediator of permeability? High Alt Med Biol. (2012) 13:153-61. doi: 10.1089/ham.2012.1052

55. Yamazaki Y, Kanekiyo T. Blood-brain barrier dysfunction and the pathogenesis of Alzheimer's disease. Int J Mol Sci. (2017) 18:965. doi: 10.3390/ijms18091965

56. Weber T, Wassertheurer S, O'Rourke MF, Haiden A, Zweiker R, Rammer $\mathrm{M}$, et al. Pulsatile hemodynamics in patients with exertional dyspnea: potentially of value in the diagnostic evaluation of suspected heart failure with preserved ejection fraction. J Am Coll Cardiol. (2013) 61:187483. doi: 10.1016/j.jacc.2013.02.013

57. Almeida OP, Garrido GJ, Beer C, Lautenschlager NT, Arnolda L, Flicker L. Cognitive and brain changes associated with ischaemic heart disease and heart failure. Eur Heart J. (2012) 33:1769-76. doi: 10.1093/eurheartj/ehr467

58. Zhu X, Smith MA, Honda K, Aliev G, Moreira PI, Nunomura A, et al. Vascular oxidative stress in Alzheimer disease. J Neurol Sci. (2007) 257:240 6. doi: 10.1016/j.jns.2007.01.039 
59. Athilingam P, Moynihan J, Chen L, D'Aoust R, Groer M, Kip K. Elevated levels of interleukin 6 and C-reactive protein associated with cognitive impairment in heart failure. Congest Heart Fail. (2013) 19:928. doi: $10.1111 /$ chf. 12007

60. Hong $\mathrm{X}, \mathrm{Bu} \mathrm{L}$, Wang $\mathrm{Y}, \mathrm{Xu} \mathrm{J}, \mathrm{Wu} \mathrm{J}$, Huang $\mathrm{Y}$, et al. Increases in the risk of cognitive impairment and alterations of cerebral betaamyloid metabolism in mouse model of heart failure. PLoS ONE. (2013) 8:e63829. doi: 10.1371/journal.pone.0063829

61. McAfoose J, Baune BT. Evidence for a cytokine model of cognitive function. Neurosci Biobehav Rev. (2009) 33:35566. doi: 10.1016/j.neubiorev.2008.10.005

62. Tangestani Fard M, Stough C. A review and hypothesized model of the mechanisms that underpin the relationship between inflammation and cognition in the elderly. Front Aging Neurosci. (2019) 11:56. doi: 10.3389/fnagi.2019.00056

63. Gonzalez P, Machado I, Vilcaes A, Caruso C, Roth GA, Schiöth $\mathrm{H}$, et al. Molecular mechanisms involved in interleukin 1-beta (IL-1 $\beta$ )-induced memory impairment Modulation by alpha-melanocytestimulating hormone ( $\alpha-\mathrm{MSH})$. Brain Behav Immun. (2013) 34:141-50. doi: 10.1016/j.bbi.2013.08.007

64. Toyama K, Koibuchi N, Uekawa K, Hasegawa Y, Kataoka K, Katayama T, et al. Apoptosis signal-regulating kinase 1 is a novel target molecule for cognitive impairment induced by chronic cerebral hypoperfusion. Arterioscler Thromb Vasc Biol. (2014) 34:616-25. doi: 10.1161/ATVBAHA.113.302440

65. Hou X, Liang X, Chen JF, Zheng J. Ecto-5'-nucleotidase (CD73) is involved in chronic cerebral hypoperfusion-induced white matter lesions and cognitive impairment by regulating glial cell activation and pro-inflammatory cytokines. Neuroscience. (2015) 297:118-26. doi: 10.1016/j.neuroscience.2015.03.033

66. Faraco G, Sugiyama Y, Lane D, Garcia-Bonilla L, Chang H, Santisteban MM, et al. Perivascular macrophages mediate the neurovascular and cognitive dysfunction associated with hypertension. J Clin Invest. (2016) 126:467489. doi: 10.1172/JCI86950

67. Vanherle L, Matuskova H, Don-Doncow N, Uhl FE, Meissner A. Improving cerebrovascular function to increase neuronal recovery in neurodegeneration associated to cardiovascular disease. Front Cell Dev Biol. (2020) 8:53. doi: 10.3389/fcell.2020.00053

68. Pun PB, Lu J, Moochhala S. Involvement of ROS in BBB dysfunction. Free Radic Res. (2009) 43:348-64. doi: 10.1080/10715760902751902

69. Durrant CS, Ruscher K, Sheppard O, Coleman MP, Özen I. Beta secretase 1-dependent amyloid precursor protein processing promotes excessive vascular sprouting through NOTCH3 signalling. Cell Death Dis. (2020) 11:98. doi: 10.1038/s41419-020-2288-4

70. Heppner FL, Ransohoff RM, Becher B. Immune attack: the role of inflammation in Alzheimer disease. Nat Rev Neurosci. (2015) 16:35872. doi: $10.1038 / \mathrm{nrn} 3880$

71. Rodriguez-Vieitez E, Saint-Aubert L, Carter SF, Almkvist O, Farid K, Schöll M, et al. Diverging longitudinal changes in astrocytosis and amyloid PET in autosomal dominant Alzheimer's disease. Brain. (2016) 139:92236. doi: 10.1093/brain/awv404

72. Frost GR, Li YM. The role of astrocytes in amyloid production and Alzheimer's disease. Open Biol. (2017) 7:228. doi: 10.1098/rsob.170228

73. Gipson CD, Olive MF. Structural and functional plasticity of dendritic spines - root or result of behavior? Genes Brain Behav. (2017) 16:10117. doi: $10.1111 /$ gbb. 12324

74. Morley JE, Farr SA. The role of amyloid-beta in the regulation of memory. Biochem Pharmacol. (2014) 88:479-85. doi: 10.1016/j.bcp.2013. 12.018

75. Toledo C, Andrade DC, Díaz HS, Inestrosa NC, Del Rio R. Neurocognitive disorders in heart failure: novel pathophysiological mechanisms underpinning memory loss and learning impairment. Mol Neurobiol. (2019) 56:8035-51. doi: 10.1007/s12035-019-01655-0

76. Meissner A, Visanji NP, Momen MA, Feng R, Francis BM, Bolz SS, et al. Tumor necrosis factor- $\alpha$ underlies loss of cortical dendritic spine density in a mouse model of congestive heart failure. J Am Heart Assoc. (2015) 4:1920. doi: 10.1161/JAHA.115.001920
77. Toledo C, Lucero C, Andrade DC, Díaz HS, Schwarz KG, Pereyra KV, et al. Cognitive impairment in heart failure is associated with altered Wnt signaling in the hippocampus. Aging (Albany NY). (2019) 11:592442. doi: 10.18632/aging.102150

78. Gallina D, Zelinka C, Fischer AJ. Glucocorticoid receptors in the retina, Müller glia and the formation of Müller glia-derived progenitors. Development. (2014) 141:3340-51. doi: 10.1242/dev.109835

79. Liori S, Arfaras-Melainis A, Bistola V, Polyzogopoulou E, Parissis J. Cognitive impairment in heart failure: clinical implications, tools of assessment, therapeutic considerations. Heart Fail Rev. (2021). [Epub ahead of print]. doi: 10.1007/s10741-021-10118-5

80. Sfera A, Osorio C. Water for thought: is there a role for aquaporin channels in delirium? Front Psychiatry. (2014) 5:57. doi: 10.3389/fpsyt.2014.00057

81. Chen Z, Zhong C. Oxidative stress in Alzheimer's disease. Neurosci Bull. (2014) 30:271-81. doi: 10.1007/s12264-013-1423-y

82. Khacho M, Clark A, Svoboda DS, MacLaurin JG, Lagace DC, Park DS, et al. Mitochondrial dysfunction underlies cognitive defects as a result of neural stem cell depletion and impaired neurogenesis. Hum Mol Genet. (2017) 26:3327-41. doi: 10.1093/hmg/ddx217

83. Khacho M, Harris R, Slack RS. Mitochondria as central regulators of neural stem cell fate and cognitive function. Nat Rev Neurosci. (2019) 20:3448. doi: 10.1038/s41583-018-0091-3

84. Maneechote C, Palee S, Kerdphoo S, Jaiwongkam T, Chattipakorn SC, Chattipakorn N. Balancing mitochondrial dynamics via increasing mitochondrial fusion attenuates infarct size and left ventricular dysfunction in rats with cardiac ischemia/reperfusion injury. Clin Sci (Lond). (2019) 133:497-513. doi: 10.1042/CS20190014

85. Jinawong K, Apaijai N, Chattipakorn N, Chattipakorn SC. Cognitive impairment in myocardial infarction and heart failure. Acta Physiol (Oxf). (2021) 232:e13642. doi: 10.1111/apha.13642

86. Kim MS, Lee GH, Kim YM, Lee BW, Nam HY, Sim UC, et al. Angiotensin II causes apoptosis of adult hippocampal neural stem cells and memory impairment through the action on AMPK-PGC1 $\alpha$ signaling in heart failure. Stem Cells Transl Med. (2017) 6:1491-503. doi: 10.1002/sctm.16-0382

87. Combs CK. Inflammation and microglia actions in Alzheimer's disease. $J$ Neuroimmune Pharmacol. (2009) 4:380-8. doi: 10.1007/s11481-009-9165-3

88. Gottesman RF, Grega MA, Bailey MM, Zeger SL, Baumgartner WA, McKhann GM, et al. Association between hypotension, low ejection fraction and cognitive performance in cardiac patients. Behav Neurol. (2010) 22:6371. doi: $10.1155 / 2010 / 725353$

89. Baldasseroni S, Mossello E, Romboli B, Orso F, Colombi C, Fumagalli S, et al. Relationship between cognitive function and 6-minute walking test in older outpatients with chronic heart failure. Aging Clin Exp Res. (2010) 22:308-13. doi: 10.1007/BF03324936

90. Myserlis PG, Malli A, Kalaitzoglou DK, Kalaitzidis G, Miligkos M, Kokkinidis DG, et al. Atrial fibrillation and cognitive function in patients with heart failure: a systematic review and meta-analysis. Heart Fail Rev. (2017) 22:1-11. doi: 10.1007/s10741-016-9587-y

91. Mueller K, Thiel F, Beutner F, Teren A, Frisch S, Ballarini $\mathrm{T}$, et al. Brain damage with heart failure: cardiac biomarker alterations and gray matter decline. Circ Res. (2020) 126:75064. doi: 10.1161/CIRCRESAHA.119.315813

92. Lee TC, Qian M, Liu Y, Graham S, Mann DL, Nakanishi K, et al. Cognitive decline over time in patients with systolic heart failure: insights from WARCEF. JACC Heart Fail. (2019) 7:1042-53. doi: 10.1016/j.jchf.2019.09.003

93. Alosco ML, Spitznagel MB, Gunstad J. Obesity as a risk factor for poor neurocognitive outcomes in older adults with heart failure. Heart Fail Rev. (2014) 19:403-11. doi: 10.1007/s10741-013-9399-2

94. Alosco ML, Spitznagel MB, Sweet LH, Josephson R, Hughes J, Gunstad J. Atrial fibrillation exacerbates cognitive dysfunction and cerebral perfusion in heart failure. Pacing Clin Electrophysiol. (2015) 38:17886. doi: $10.1111 /$ pace. 12543

95. Stefansdottir H, Arnar DO, Aspelund T, Sigurdsson S, Jonsdottir MK, Hjaltason $\mathrm{H}$, et al. Atrial fibrillation is associated with reduced brain volume and cognitive function independent of cerebral infarcts. Stroke. (2013) 44:1020-5. doi: 10.1161/STROKEAHA.12.679381 
96. Brouwer-Brolsma EM, van de Rest O, Tieland M, van der Zwaluw NL, Steegenga WT, Adam JJ, et al. Serum 25-hydroxyvitamin D is associated with cognitive executive function in Dutch prefrail and frail elderly: a crosssectional study exploring the associations of 25-hydroxyvitamin D with glucose metabolism, cognitive performance and depression. J Am Med Dir Assoc. (2013) 14:852.e859-17. doi: 10.1016/j.jamda.2013.06.010

97. Langlais PJ, Savage LM. Thiamine deficiency in rats produces cognitive and memory deficits on spatial tasks that correlate with tissue loss in diencephalon, cortex and white matter. Behav Brain Res. (1995) 68:7589. doi: 10.1016/0166-4328(94)00162-9

98. Matté C, Mackedanz V, Stefanello FM, Scherer EB, Andreazza AC, Zanotto $\mathrm{C}$, et al. Chronic hyperhomocysteinemia alters antioxidant defenses and increases DNA damage in brain and blood of rats: protective effect of folic acid. Neurochem Int. (2009) 54:7-13. doi: 10.1016/j.neuint.2008.08.011

99. Hugo J, Ganguli M. Dementia and cognitive impairment: epidemiology, diagnosis, and treatment. Clin Geriatr Med. (2014) 30:421-42. doi: 10.1016/j.cger.2014.04.001

100. Jessen F, Amariglio RE, Buckley RF, van der Flier WM, Han Y, Molinuevo $\mathrm{JL}$, et al. The characterisation of subjective cognitive decline. Lancet Neurol. (2020) 19:271-8. doi: 10.1016/S1474-4422(19)30368-0

101. Dodson JA, Truong TT, Towle VR, Kerins G, Chaudhry SI. Cognitive impairment in older adults with heart failure: prevalence, documentation, and impact on outcomes. Am J Med. (2013) 126:120-6. doi: 10.1016/j.amjmed.2012.05.029

102. Folstein MF, Folstein SE, McHugh PR. "Mini-mental state" A practical method for grading the cognitive state of patients for the clinician. J Psychiatr Res. (1975) 12:189-98. doi: 10.1016/0022-3956(75)90026-6

103. Rosli R, Tan MP, Gray WK, Subramanian P, Chin AV. Cognitive assessment tools in Asia: a systematic review. Int Psychogeriatr. (2016) 28:189210. doi: $10.1017 /$ S1041610215001635

104. Mao HF, Chang LH, Tsai AY, Huang WW, Tang LY, Lee HJ, et al. Diagnostic accuracy of instrumental activities of daily living for dementia in community-dwelling older adults. Age Ageing. (2018) 47:551-7. doi: 10.1093/ageing/afy021

105. Huo Z, Lin J, Bat BKK, Chan JYC, Tsoi KKF, Yip BHK. Diagnostic accuracy of dementia screening tools in the Chinese population: a systematic review and meta-analysis of 167 diagnostic studies. Age Ageing. (2021) 50:1093101. doi: 10.1093/ageing/afab005

106. Holsinger T, Deveau J, Boustani M, Williams JW, Jr. Does this patient have dementia? JAMA. (2007) 297:2391-404. doi: 10.1001/jama.297. 21.2391

107. Nasreddine ZS, Phillips NA, Bédirian V, Charbonneau S, Whitehead V, Collin I, et al. The Montreal Cognitive Assessment, MoCA: a brief screening tool for mild cognitive impairment. J Am Geriatr Soc. (2005) 53:6959. doi: 10.1111/j.1532-5415.2005.53221.x

108. Borson S, Scanlan J, Brush M, Vitaliano P, Dokmak A. The minicog: a cognitive 'vital signs' measure for dementia screening in multi-lingual elderly. Int $J$ Geriatr Psychiatry. (2000) 15:10217. doi: 10.1002/1099-1166(200011)15:11<1021::aid-gps234>3.0.co;2-6

109. Chertkow H, Nasreddine Z, Joanette Y, Drolet V, Kirk J, Massoud $\mathrm{F}$, et al. Mild cognitive impairment and cognitive impairment, no dementia: part A, concept and diagnosis. Alzheimers Dement. (2007) 3:26682. doi: 10.1016/j.jalz.2007.07.013

110. Tariq SH, Tumosa N, Chibnall JT, Perry MH, III, Morley JE. Comparison of the Saint Louis University mental status examination and the mini-mental state examination for detecting dementia and mild neurocognitive disorder-a pilot study. Am J Geriatr Psychiatry. (2006) 14:900-10. doi: 10.1097/01.JGP.0000221510.33817.86

111. Malmstrom TK, Voss VB, Cruz-Oliver DM, Cummings-Vaughn LA, Tumosa N, Grossberg GT, et al. The rapid cognitive screen (RCS): a pointof-care screening for dementia and mild cognitive impairment. J Nutr Health Aging. (2015) 19:741-4. doi: 10.1007/s12603-015-0564-2

112. Radanovic M, Facco G, Forlenza OV. Sensitivity and specificity of a briefer version of the Cambridge Cognitive Examination (CAMCog-Short) in the detection of cognitive decline in the elderly: an exploratory study. Int $J$ Geriatr Psychiatry. (2018) 33:769-78. doi: 10.1002/gps.4857

113. Aprahamian I, Diniz BS, Izbicki R, Radanovic M, Nunes PV, Forlenza OV. Optimizing the CAMCOG test in the screening for mild cognitive impairment and incipient dementia: saving time with relevant domains. Int J Geriatr Psychiatry. (2011) 26:403-8. doi: 10.1002/gps.2540

114. Nunes PV, Diniz BS, Radanovic M, Abreu ID, Borelli DT, Yassuda MS, et al. CAMcog as a screening tool for diagnosis of mild cognitive impairment and dementia in a Brazilian clinical sample of moderate to high education. Int $J$ Geriatr Psychiatry. (2008) 23:1127-33. doi: 10.1002/gps.2038

115. Alagiakrishnan K, Mah D, Dyck JR, Senthilselvan A, Ezekowitz J. Comparison of two commonly used clinical cognitive screening tests to diagnose mild cognitive impairment in heart failure with the golden standard European Consortium Criteria. Int J Cardiol. (2017) 228:55862. doi: 10.1016/j.ijcard.2016.11.193

116. Hawkins MA, Gathright EC, Gunstad J, Dolansky MA, Redle JD, Josephson $\mathrm{R}$, et al. The MoCA and MMSE as screeners for cognitive impairment in a heart failure population: a study with comprehensive neuropsychological testing. Heart Lung. (2014) 43:462-8. doi: 10.1016/j.hrtlng.2014.05.011

117. Almeida OP, Beer C, Lautenschlager NT, Arnolda L, Alfonso H, Flicker L. Two-year course of cognitive function and mood in adults with congestive heart failure and coronary artery disease: the Heart-Mind Study. Int Psychogeriatr. (2012) 24:38-47. doi: 10.1017/S1041610211001657

118. Saito H, Yamashita M, Endo Y, Mizukami A, Yoshioka K, Hashimoto T, et al. Cognitive impairment measured by Mini-Cog provides additive prognostic information in elderly patients with heart failure. J Cardiol. (2020) 76:3506. doi: $10.1016 / j . j j c c .2020 .06 .016$

119. Blennow K, Hampel H. CSF markers for incipient Alzheimer's disease. Lancet Neurol. (2003) 2:605-13. doi: 10.1016/S1474-4422(03)00530-1

120. Ritchie C, Smailagic N, Noel-Storr AH, Takwoingi Y, Flicker L, Mason SE, et al. Plasma and cerebrospinal fluid amyloid beta for the diagnosis of Alzheimer's disease dementia and other dementias in people with mild cognitive impairment (MCI). Cochrane Database Syst Rev. (2014) 2014:Cd008782. doi: 10.1002/14651858.CD008782.pub4

121. Gustafson DR, Skoog I, Rosengren L, Zetterberg H, Blennow K. Cerebrospinal fluid beta-amyloid 1-42 concentration may predict cognitive decline in older women. J Neurol Neurosurg Psychiatry. (2007) 78:4614. doi: 10.1136/jnnp.2006.100529

122. Stomrud E, Hansson O, Blennow K, Minthon L, Londos E. Cerebrospinal fluid biomarkers predict decline in subjective cognitive function over 3 years in healthy elderly. Dement Geriatr Cogn Disord. (2007) 24:11824. doi: 10.1159/000105017

123. Blennow K, Zetterberg H. Cerebrospinal fluid biomarkers for Alzheimer's disease. J Alzheimers Dis. (2009) 18:413-7. doi: 10.3233/JAD-2009-1177

124. Mitchell AJ. CSF phosphorylated tau in the diagnosis and prognosis of mild cognitive impairment and Alzheimer's disease: a metaanalysis of 51 studies. J Neurol Neurosurg Psychiatry. (2009) 80:966-75. doi: 10.1136/jnnp.2008.167791

125. Zheng YM, Zhao YY, Zhang T, Hou XH, Bi YL, Ma YH, et al. Left ventricular ejection fraction and cerebrospinal fluid biomarkers of Alzheimer's disease pathology in cognitively normal older adults: the CABLE study. J Alzheimers Dis. (2021) 81:743-50. doi: 10.3233/JAD-201222

126. Chojdak-Lukasiewicz J, Malodobra-Mazur M, Zimny A, Noga L, Paradowski B. Plasma tau protein and Abeta42 level as markers of cognitive impairment in patients with Parkinson's disease. Adv Clin Exp Med. (2020) 29:11521. doi: $10.17219 /$ acem/112058

127. Chen TB, Lee YJ, Lin SY, Chen JP, Hu CJ, Wang PN, et al. Plasma Abeta42 and total tau predict cognitive decline in amnestic mild cognitive impairment. Sci Rep. (2019) 9:13984. doi: 10.1038/s41598-019-50315-9

128. Bayes-Genis A, Barallat J, de Antonio M, Domingo M, Zamora E, J Vila, et al. Bloodstream amyloid-beta (1-40) peptide, cognition, and outcomes in heart failure. Rev Esp Cardiol (Engl Ed). (2017) 70:92432. doi: 10.1016/j.rec.2017.02.021

129. Redwine LS, Pung MA, Wilson K, Chinh K, Duffy AR. Differential peripheral inflammatory factors associated with cognitive function in patients with heart failure. Neuroimmunomodulation. (2018) 25:14652. doi: $10.1159 / 000493142$

130. Redwine LS, Pung MA, Wilson K, Bangen KJ, Delano-Wood L, Hurwitz B. An exploratory randomized sub-study of light-to-moderate intensity exercise on cognitive function, depression symptoms and inflammation in older adults with heart failure. J Psychosom Res. (2020) 128:109883. doi: 10.1016/j.jpsychores.2019.109883 
131. Chhatwal JP, Schultz AP, Dang Y, Ostaszewski B, Liu L, Yang HS, et al. Plasma N-terminal tau fragment levels predict future cognitive decline and neurodegeneration in healthy elderly individuals. Nat Commun. (2020) 11:6024. doi: 10.1038/s41467-020-19543-w

132. Chen Z, Mengel D, Keshavan A, Rissman RA, Billinton A, Perkinton M, et al. Learnings about the complexity of extracellular tau aid development of a blood-based screen for Alzheimer's disease. Alzheimers Dement. (2019) 15:487-96. doi: 10.1016/j.jalz.2018.09.010

133. Varma VR, Oommen AM, Varma S, Casanova R, An Y, Andrews RM, et al. Brain and blood metabolite signatures of pathology and progression in Alzheimer disease: a targeted metabolomics study. PLoS Med. (2018) 15:e1002482. doi: 10.1371/journal.pmed.1002482

134. Abdullah M, Kimura N, Akatsu H, Hashizume Y, Ferdous T, Tachita T, et al. Flotillin is a novel diagnostic blood marker of Alzheimer's disease. $J$ Alzheimers Dis. (2019) 72:1165-76. doi: 10.3233/JAD-190908

135. Debette S, Schilling S, Duperron MG, Larsson SC, Markus HS. Clinical significance of magnetic resonance imaging markers of vascular brain injury: a systematic review and meta-analysis. JAMA Neurol. (2019) 76:8194. doi: 10.1001/jamaneurol.2018.3122

136. Alosco ML, Brickman AM, Spitznagel MB, Garcia SL, Narkhede A, Griffith EY, et al. Cerebral perfusion is associated with white matter hyperintensities in older adults with heart failure. Congest Heart Fail. (2013) 19:E2934. doi: $10.1111 /$ chf. 12025

137. Beer C, Ebenezer E, Fenner S, Lautenschlager NT, Arnolda L, Flicker L, et al. Contributors to cognitive impairment in congestive heart failure: a pilot case-control study. Intern Med J. (2009) 39:600-5. doi: 10.1111/j.1445-5994.2008.01790.x

138. Stegmann T, Chu ML, Witte VA, Villringer A, Kumral D, Riedel-Heller SG, et al. Heart failure is independently associated with white matter lesions: insights from the population-based LIFE-Adult Study. ESC Heart Fail. (2021) 8:697-704. doi: 10.1002/ehf2.13166

139. Kumar R, Woo MA, Macey PM, Fonarow GC, Hamilton MA, Harper RM. Brain axonal and myelin evaluation in heart failure. J Neurol Sci. (2011) 307:106-13. doi: 10.1016/j.jns.2011.04.028

140. Almeida OP, Garrido GJ, Etherton-Beer C, Lautenschlager NT, Arnolda L, Alfonso $\mathrm{H}$, et al. Brain and mood changes over 2 years in healthy controls and adults with heart failure and ischaemic heart disease. Eur J Heart Fail. (2013) 15:850-8. doi: 10.1093/eurjhf/hft029

141. Frey A, Homola GA, Henneges C, Mühlbauer L, Sell R, Kraft P, et al. Temporal changes in total and hippocampal brain volume and cognitive function in patients with chronic heart failure-the COGNITIONMATTERS-HF cohort study. Eur Heart J. (2021) 42:1569-78. doi: 10.1093/eurheartj/ehab003

142. Alves TC, Busatto GF. Regional cerebral blood flow reductions, heart failure and Alzheimer's disease. Neurol Res. (2006) 28:579-87. doi: 10.1179/016164106X130416

143. Yun M, Nie B, Wen W, Zhu Z, Liu H, Nie S, et al. Assessment of cerebral glucose metabolism in patients with heart failure by (18)FFDG PET/CT imaging. J Nucl Cardiol. (2020). [Epub ahead of print]. doi: 10.1007/s12350-020-02258-2

144. Fox MD, Raichle ME. Spontaneous fluctuations in brain activity observed with functional magnetic resonance imaging. Nat Rev Neurosci. (2007) 8:700-11. doi: 10.1038/nrn2201

145. Singh PK, Chen ZL, Ghosh D, Strickland S, Norris EH. Increased plasma bradykinin level is associated with cognitive impairment in Alzheimer's patients. Neurobiol Dis. (2020) 139:104833. doi: 10.1016/j.nbd.2020. 104833

146. Cannon JA, Shen L, Jhund PS, Kristensen SL, Kober L, Chen F, et al. Dementia-related adverse events in PARADIGM-HF and other trials in heart failure with reduced ejection fraction. Eur J Heart Fail. (2017) 19:12937. doi: 10.1002/ejhf.687

147. Poorgolizadeh E, Homayouni Moghadam F, Dormiani K, Rezaei N, Nasr-Esfahani MH. Do neprilysin inhibitors walk the line? Heart ameliorative but brain threatening! Eur J Pharmacol. (2021) 894:173851. doi: 10.1016/j.ejphar.2021.173851

148. Mui JV, Zhou J, Lee S, Leung KSK, Lee TTL, Chou OHI, et al. Sodium-glucose cotransporter 2 (SGLT2) inhibitors vs. dipeptidyl peptidase-4 (DPP4) inhibitors for new-onset dementia: a propensity score-matched populationbased study with competing risk analysis. Front Cardiovasc Med. (2021) 8:747620. doi: 10.3389/fcvm.2021.747620

149. Yamada K, Uchida S, Takahashi S, Takayama M, Nagata Y, Suzuki N, et al. Effect of a centrally active angiotensin-converting enzyme inhibitor, perindopril, on cognitive performance in a mouse model of Alzheimer's disease. Brain Res. (2010) 1352:176-86. doi: 10.1016/j.brainres.2010.07.006

150. Zuccala G, Onder G, Marzetti E, Monaco MR, Cesari M, Cocchi A, et al. Use of angiotensin-converting enzyme inhibitors and variations in cognitive performance among patients with heart failure. Eur Heart J. (2005) 26:22633. doi: 10.1093/eurheartj/ehi058

151. Soto ME, van Kan GA, Nourhashemi F, Gillette-Guyonnet S, Cesari M, Cantet C, et al. Angiotensin-converting enzyme inhibitors and Alzheimer's disease progression in older adults: results from the Reseau sur la Maladie d'Alzheimer Francais cohort. J Am Geriatr Soc. (2013) 61:14828. doi: 10.1111 /jgs. 12415

152. Hierro-Bujalance C, Infante-Garcia C, Del Marco A, Herrera M, Carranza-Naval MJ, Suarez J, et al. Empagliflozin reduces vascular damage and cognitive impairment in a mixed murine model of Alzheimer's disease and type 2 diabetes. Alzheimers Res Ther. (2020) 12:40. doi: 10.1186/s13195-020-00607-4

153. McMurray JJV, Solomon SD, Inzucchi SE, Kober L, Kosiborod MN, Martinez FA, et al. Dapagliflozin in patients with heart failure and reduced ejection fraction. N Engl J Med. (2019) 381:1995-2008. doi: 10.1056/NEJMoa1911303

154. Packer M, Anker SD, Butler J, Filippatos G, Pocock SJ, Carson P, et al. Cardiovascular and renal outcomes with empagliflozin in heart failure. $N$ Engl J Med. (2020) 383:1413-24. doi: 10.1056/NEJMoa2022190

155. Fouchier S, Dallinga-Thie G, Meijers J, Zelcer N, Kastelein J, Defesche J, et al. Mutations in STAP1 are associated with autosomal dominant hypercholesterolemia. Circ Res. (2014) 115:552-5. doi: 10.1161/CIRCRESAHA.115.304660

156. Perna S, Mainardi M, Astrone P, Gozzer C, Biava A, Bacchio R, et al. 12-month effects of incretins versus SGLT2-Inhibitors on cognitive performance and metabolic profile A randomized clinical trial in the elderly with Type-2 diabetes mellitus. Clin Pharmacol. (2018) 10:14151. doi: 10.2147/CPAA.S164785

157. Hajjar I, Hart M, Chen YL, Mack W, Milberg W, Chui H, et al. Effect of antihypertensive therapy on cognitive function in early executive cognitive impairment: a double-blind randomized clinical trial. Arch Intern Med. (2012) 172:442-4. doi: 10.1001/archinternmed.2011.1391

158. Yasar S, Xia J, Yao W, Furberg CD, Xue QL, Mercado CI, et al. Antihypertensive drugs decrease risk of Alzheimer disease: Ginkgo evaluation of memory study. Neurology. (2013) 81:896-903. doi: 10.1212/WNL.0b013e3182a35228

159. Hajjar I, Okafor M, McDaniel D, Obideen M, Dee E, Shokouhi $M$, et al. Effects of candesartan vs. lisinopril on neurocognitive function in older adults with executive mild cognitive impairment: a randomized clinical trial. JAMA Netw Open. (2020) 3:e2012252. doi: 10.1001/jamanetworkopen.2020.12252

160. Ouk M, Wu CY, Rabin JS, Edwards JD, Ramirez J, Masellis $\mathrm{M}$, et al. Associations between brain amyloid accumulation and the use of angiotensin-converting enzyme inhibitors versus angiotensin receptor blockers. Neurobiol Aging. (2021) 100:22-31. doi: 10.1016/j.neurobiolaging.2020.12.011

161. Luijendijk HJ, Koolman X. The incentive to publish negative studies: how beta-blockers and depression got stuck in the publication cycle. J Clin Epidemiol. (2012) 65:488-92. doi: 10.1016/j.jclinepi.2011.06.022

162. Holm H, Ricci F, Di Martino G, Bachus E, Nilsson ED, Ballerini $\mathrm{P}$, et al. Beta-blocker therapy and risk of vascular dementia: a population-based prospective study. Vascul Pharmacol. (2020) 125-126:106649. doi: 10.1016/j.vph.2020.106649

163. Wingenfeld K, Otte C. Mineralocorticoid receptor function and cognition in health and disease. Psychoneuroendocrinology. (2019) 105:25-35. doi: 10.1016/j.psyneuen.2018.09.010

164. Doehner W, Ural D, Haeusler KG, Celutkiene J, Bestetti R, Cavusoglu Y, et al. Heart and brain interaction in patients with heart failure: overview and proposal for a taxonomy A position paper from the Study Group on 
Heart and Brain Interaction of the Heart Failure Association. Eur J Heart Fail. (2018) 20:199-215. doi: 10.1002/ejhf.1100

165. Wang $X$, Sun $G$, Feng $T$, Zhang J, Huang $X$, Wang $T$, et al. Sodium oligomannate therapeutically remodels gut microbiota and suppresses gut bacterial amino acids-shaped neuroinflammation to inhibit Alzheimer's disease progression. Cell Res. (2019) 29:787-803. doi: 10.1038/s41422-019-0216-x

166. Xiao S, Chan P, Wang T, Hong Z, Wang S, Kuang W, et al. A 36week multicenter, randomized, double-blind, placebo-controlled, parallel-group, phase 3 clinical trial of sodium oligomannate for mild-to-moderate Alzheimer's dementia. Alzheimers Res Ther. (2021) 13:62. doi: 10.1186/s13195-021-00795-7

167. Jiang T, Gao L, Lu J, Zhang YD. ACE2-Ang-(1-7)-mas axis in brain: a potential target for prevention and treatment of ischemic stroke. Curr Neuropharmacol. (2013) 11:209-17. doi: 10.2174/1570159X11311020007

168. Hay M, Polt R, Heien ML, Vanderah TW, Largent-Milnes TM, Rodgers $\mathrm{K}$, et al. A novel angiotensin-(1-7) glycosylated mas receptor agonist for treating vascular cognitive impairment and inflammation-related memory dysfunction. J Pharmacol Exp Ther. (2019) 369:9-25. doi: 10.1124/jpet.118.254854

169. Hay M, Vanderah TW, Samareh-Jahani F, Constantopoulos E, Uprety AR, Barnes CA, et al. Cognitive impairment in heart failure: a protective role for angiotensin-(1-7). Behav Neurosci. (2017) 131:99114. doi: $10.1037 / \mathrm{bne} 0000182$

170. Lidington D, Fares JC, Uhl FE, Dinh DD, Kroetsch JT, Sauve M, et al. CFTR therapeutics normalize cerebral perfusion deficits in mouse models of heart failure and subarachnoid hemorrhage. JACC Basic Transl Sci. (2019) 4:940-58. doi: 10.1016/j.jacbts.2019.07.004

171. Alosco ML, Brickman AM, Spitznagel MB, Sweet LH, Josephson R, Griffith EY, et al. Daily physical activity is associated with subcortical brain volume and cognition in heart failure. J Int Neuropsychol Soc. (2015) 21:85160. doi: $10.1017 /$ S1355617715000697

172. Ngandu T, Lehtisalo J, Solomon A, Levälahti E, Ahtiluoto S, Antikainen R, et al. A 2 year multidomain intervention of diet, exercise, cognitive training, and vascular risk monitoring versus control to prevent cognitive decline in at-risk elderly people (FINGER): a randomised controlled trial. Lancet. (2015) 385:2255-63. doi: 10.1016/S0140-6736(15)60461-5

173. Hoth KF, Poppas A, Ellison KE, Paul RH, Sokobin A, Cho Y, et al. Link between change in cognition and left ventricular function following cardiac resynchronization therapy. J Cardiopulm Rehabil Prev. (2010) 30:4018. doi: 10.1097/HCR.0b013e3181e1739a

174. Zimpfer D, Wieselthaler G, Czerny M, Fakin R, Haider D, Zrunek P, et al. Neurocognitive function in patients with ventricular assist devices: a comparison of pulsatile and continuous blood flow devices. ASAIO J. (2006) 52:24-7. doi: 10.1097/01.mat.0000191334.51375.7e

175. Jin MN, Kim TH, Kang KW, Yu HT, Uhm JS, Joung B, et al. Atrial fibrillation catheter ablation improves 1-year follow-up cognitive function, especially in patients with impaired cognitive function. Circ Arrhythm Electrophysiol. (2019) 12:e007197. doi: 10.1161/CIRCEP.119.007197

Conflict of Interest: The authors declare that the research was conducted in the absence of any commercial or financial relationships that could be construed as a potential conflict of interest.

Publisher's Note: All claims expressed in this article are solely those of the authors and do not necessarily represent those of their affiliated organizations, or those of the publisher, the editors and the reviewers. Any product that may be evaluated in this article, or claim that may be made by its manufacturer, is not guaranteed or endorsed by the publisher.

Copyright $\odot 2022$ Yang, Sun, Wang, Yan, Zheng and Ren. This is an open-access article distributed under the terms of the Creative Commons Attribution License (CC $B Y)$. The use, distribution or reproduction in other forums is permitted, provided the original author(s) and the copyright owner(s) are credited and that the original publication in this journal is cited, in accordance with accepted academic practice. No use, distribution or reproduction is permitted which does not comply with these terms. 


\section{GLOSSARY}

$\mathrm{AD}$, Alzheimer's disease; $\mathrm{A} \beta$, amyloid- $\beta$; ATP, adenosine triphosphate; ACEI, angiotensin converting enzyme inhibitor; ACE2, angiotensin-converting enzyme 2; AF, atrial fibrillation; Ang-II, angiotensin II; Ang-(1-7), angiotensin-(1-7); APP, amyloid precursor protein; ARB, angiotensin II receptor blocker; ARNI, angiotensin receptor neprilysin inhibitor; $\mathrm{BBB}$, blood-brain barrier; BMI, body mass index; BNP, brain natriuretic peptide; $\mathrm{BP}$, blood pressure; $\mathrm{CAMCOG}$, Cambridge cognitive examination; $\mathrm{CBF}$, cerebral blood flow; CFTR, cystic fibrosis transmembrane conductance regulator; $\mathrm{CI}$, cognitive impairment; CO, cardiac out; CRT, cardiac resynchronization therapy; CSF, cerebrospinal fluid; DM, diabetes mellitus; DPP4, dipeptidyl peptidase-4; DTI, diffusion tensor imaging; FAQ, functional activities questionnaire; fMRI, functional magnetic resonance imaging; GMD, gray matter density; HF, heartfailure; HFpEF, heart failure with preserved ejection fraction; HFrEF, heart failure with reduced ejection fraction;
HIF-1, hypoxia inducible factor-1; IL, interleukin; LVEF, left ventricular ejection fraction; MCI, mild cognitive impairment; MMSE, mini-mental state examination; MoCA, Montreal cognitive assessment; MRI, magnetic resonance imaging; MTA, medial temporal lobe atrophy; NIRS, near-infrared spectroscopy; NPI-Q, neuropsychiatric inventory questionnaire; NT-proBNP, N-terminal pro-brain natriuretic peptide; pGSK3 $\beta$, phosphorylated glycogen synthase kinase $3 \beta$; PNA5, ang-1-6-O-Ser-Glc-NH2; PVM, perivascular macrophage; QoL, quality of life; RAS, renin angiotensin system; RCS, rapid cognitive screen; SGLT2, sodium glucose co-transporter 2; SLUMS, Saint Louis University mental status; ROS, subsequent reactive oxygen species; SPECT, single photon emission computed tomography; TLR-4, toll-like receptor-4; TNF- $\alpha$, tumor necrosis factor- $\alpha$, TSPO, translocator protein; VEGF-1, vascular endothelial growth factor-1; WMH, white matter hyperintensities; WML, white matter lesions; BACE, $\beta$-site amyloid precursor protein-cleaving enzyme-1; 6MWT, 6-minute walk test. 